\title{
El desempeño de las empresas transnacionales: evidencia para la industria manufacturera de Chile
}

\author{
Sebastián Vergara $M$.
}

RESUMEN

En este artículo se analiza el desempeño de las empresas transnacionales en la industria manufacturera chilena. Los resultados muestran que las subsidiarias de empresas con capital extranjero poseen mayor nivel de productividad que las empresas locales, pero no así en su crecimiento. Asimismo, que entre las empresas transnacionales y locales no existen diferencias significativas de sobrevivencia en el mercado. Empero, aquellas de propiedad mayoritariamente extranjera, pequeñas y de baja productividad sí presentan una probabilidad más elevada de salida, evidenciando un comportamiento de tipo footloose respecto de sus contrapartes locales. Esto se vincula a menores niveles de rentabilidad para este grupo de empresas transnacionales. Por último, los resultados sugieren que las empresas transnacionales no siempre tienen más altos niveles de rentabilidad respecto de las firmas locales. Más aún, pareciera que pueden explotar sus ventajas -en términos relativos a las empresas locales - solo en los mayores cuantiles de la distribución de rentabilidad.

PALABRAS CLAVES

CLASIFICACIÓN JEL
Empresas transnacionales, industria, productos manufacturados, productividad, ganancia, evaluación, datos estadísticos, Chile

L25, F23, C21

Sebastián Vergara M. es oficial de asuntos económicos del Departamento de Asuntos Económicos y Sociales (DESA) de las Naciones Unidas. vergaras@un.org 


\section{I}

\section{Introducción}

En las últimas décadas, las empresas transnacionales se han convertido en agentes relevantes en materia de comercio, innovación, tecnología y cadenas de valor a nivel global, y también en actores centrales en el proceso de desarrollo de muchos países (Cohen, 2007; UNCTAD, 2005, Narula y Lall, 2006). Una de las teorías predominantes para explicar el fenómeno de las empresas transnacionales se relaciona directamente con la existencia de ventajas de propiedad, localización e internacionalización (Dunning, 2000) ${ }^{1}$. La implicancia directa es que las subsidiarias de empresas transnacionales deberían tener un mejor desempeño en las economías receptoras en comparación con las empresas locales - por ejemplo, en términos de productividad y rentabilidad-, debido a sus mayores niveles de tecnología, capacidades y conocimientos (know how) en los mercados internacionales.

Sin embargo, estas consideraciones deben tomarse con cuidado, ya que la condición de empresa vinculada a capital extranjero no garantiza per se un desempeño relativo superior al de las firmas locales. En primer lugar, las subsidiarias de empresas transnacionales son, al igual que las empresas locales, un conjunto amplio y heterogéneo de empresas con diferentes características y capacidades. Segundo, existen factores que pueden afectar negativamente a su desempeño, como el desconocimiento del mercado local y sus patrones de competencia. De hecho, esto puede ser especialmente relevante en países en desarrollo con características particulares en materia de proveedores, infraestructura, mercado laboral e informalidad. Tercero, en la literatura reciente se observa que el flujo de conocimiento en una empresa transnacional constituye un proceso complejo y difícil, y no es posible asumir que este fluya libremente entre la casa matriz y las subsidiarias. Es decir, las ventajas de propiedad por parte de las empresas transnacionales podrían quedar localizadas solo en sus operaciones productivas más avanzadas. Por ejemplo, Hobday y Rush (2007) enfatizan el grado de autonomía de las subsidiarias y su integración en estrategias corporativas descentralizadas de las casas matrices, como aspectos

\footnotetext{
$\square$ Se agradecen los comentarios de Miguel Torres y de un árbitro anónimo.

1 Para una visión general de la literatura vinculada a empresas transnacionales, véanse Caves (1996) y Markusen (2002).
}

que determinan el flujo de conocimiento entre la casa matriz y las subsidiarias. Por su parte, Marín y Arza (2009) discuten el papel de estas últimas en términos de su capacidad de interconectar dos redes de conocimiento, el global y el nacional. Estos factores cuestionan el supuesto de que las empresas subsidiarias de empresas transnacionales necesariamente tengan un desempeño productivo superior al de las empresas locales.

En América Latina existe amplia literatura sobre inversión extranjera directa (IED) y las empresas transnacionales, y en particular con respecto a sectores de operación, tipo de actividades, modos de entrada y estrategias corporativas que explican su posicionamiento regional (CEPAL, 2012²; Gallagher y Chudnovsky, 2009; Moran, Graham y Blomstrom, 2005). Sin embargo, poco se sabe de la actividad productiva de las empresas transnacionales sobre la base de indicadores de desempeño comparable con las empresas locales. Más aún, la evidencia que existe a este respecto suele concentrarse solo en un reducido grupo de grandes empresas transnacionales, que operan en mercados oligopólicos de servicios con altos grados de concentración - como energía y telecomunicaciones-, donde la regulación juega un papel especialmente relevante en los patrones de competencia y en la determinación de la rentabilidad. Es importante profundizar en este aspecto dado el papel que estas empresas protagonizan en la conformación de la estructura productiva de los países de la región, lo que además es fundamental para comprender sus potenciales efectos en las economías receptoras. De hecho, existe una vasta literatura en que se procura comprender los efectos de las actividades de las empresas transnacionales en las economías receptoras, y sobre todo con respecto a encadenamientos, transferencias de tecnología y creación y fortalecimiento de capacidades locales en países en desarrollo. La evidencia, no obstante, sigue siendo heterogénea y, en muchos casos, contradictoria. En ese sentido, pareciera que los efectos no solo se vinculan a las características de las empresas transnacionales en términos de estrategias corporativas, sectores y tipos

\footnotetext{
2 Véanse las diferentes ediciones del informe La inversión extranjera en América Latina y el Caribe publicado anualmente por la División de Desarrollo Productivo y Empresarial de la CEPAL.
} 
de actividades productivas y de servicios, sino también a la capacidad de absorción de las economías (Lipsey, 2002; Moran, Graham y Blomstrom, 2005) ${ }^{3}$.

En tal contexto, en este artículo se analiza el desempeño de las subsidiarias de empresas transnacionales en relación con las empresas locales en el sector manufacturero de Chile, sobre la base de tres indicadores:

\footnotetext{
${ }^{3}$ Los efectos de las operaciones de empresas transnacionales pueden ser directos o indirectos. Los efectos directos se refieren a aquellos que no dependen especialmente de la interacción entre las empresas transnacionales y la capacidad de absorción. Entre estos se pueden mencionar el mayor acceso de divisas, el aumento de la formación bruta de capital fijo, el incremento de la oferta (mayor producción y acceso a bienes y servicios, e incremento del empleo) y los vinculados a una expansión de las exportaciones y a potenciales repercusiones en el medio ambiente. Por su parte, los efectos indirectos están determinados por la capacidad de absorción del país receptor: capital humano, capacidades de la base tecnológica, infraestructura, proveedores locales, estructura productiva y el sistema nacional de innovación. Entre estos efectos se pueden mencionar los encadenamientos productivos, las transferencias de tecnología y la creación y el fortalecimiento de capacidades locales (CEPAL, 2011, pág. 29).
}

productividad, sobrevivencia en el mercado y rentabilidad $^{4}$. El estudio se organiza de la siguiente manera: en la sección II se realiza una breve revisión de la literatura, mientras que en la sección III se exponen algunas características generales de la presencia de empresas transnacionales en la industria manufacturera chilena. Luego, en la sección IV se describen las diferentes metodologías empíricas y en la sección $\mathrm{V}$ se discuten los resultados de las estimaciones. Por último, en la sección VI se presentan las principales conclusiones.

\footnotetext{
${ }^{4}$ Estudiar en forma complementaria la productividad y la rentabilidad de las empresas se justifica por el hecho de que con ambas se miden diferentes aspectos operativos. Por una parte, la productividad está más estrechamente ligada a aspectos productivos y técnicos, vinculando producción con un determinado nivel de insumos. La rentabilidad, en cambio, se vincula a aspectos económicos y financieros a través de ingresos y costos operacionales. La correlación entre ambas variables muestra que en cierta medida los aumentos de productividad se traducen en incrementos de rentabilidad, pero no necesariamente esto es siempre así. Las empresas privadas procuran, en su gran mayoría, exclusivamente maximizar la rentabilidad de sus operaciones.
}

\section{Breve revisión de la literatura}

Existen diversos estudios en que se compara el desempeño de las empresas transnacionales con el de las empresas locales, especialmente en países desarrollados. En términos de productividad, donde la literatura es relativamente más extensa y sobre todo en el sector manufacturero, existe amplia evidencia de que las ventajas que poseen las empresas transnacionales, tanto de capital extranjero como de capital doméstico ${ }^{5}$, se traducen en mayor productividad con respecto a las locales. Esto se confirma utilizando diferentes medidas, como indicadores de eficiencia técnica, productividad laboral o productividad total de los factores (PTF). Por ejemplo, Baldwin, Lipsey y Richards (1998) destacan que las subsidiarias de empresas transnacionales en los Estados Unidos de América son más intensivas en capital, pagan salarios más altos y muestran niveles de productividad laboral más elevados, incluso al controlar por factores como tamaño, sector y otros. Por su parte, Temouri, Driffield e Higón (2008) analizan la PTF en Alemania en el período

5 Las empresas transnacionales de capital doméstico son aquellas empresas locales que realizan operaciones en mercados internacionales.
1995-2004. Por medio de evidencia semiparamétrica para controlar por problemas de endogeneidad, los autores muestran que la condición de empresa multinacional (tanto de capital nacional como de extranjero) explica en forma considerable las diferencias en productividad a nivel de empresas.

Asimismo, con respecto al Reino Unido de Gran Bretaña e Irlanda del Norte, Girma, Kneller y Pisu (2005) muestran que tanto las subsidiarias de empresas transnacionales como las transnacionales británicas son más productivas que las empresas exportadoras, y estas a su vez más productivas que las no exportadoras ${ }^{6}$. De esta manera, en la literatura referida a países desarrollados se diferencia entre empresas transnacionales (extranjeras o locales) y las empresas puramente domésticas, en particular debido a que un número importante de las empresas locales efectúan operaciones internacionales.

\footnotetext{
${ }^{6}$ Dimelis y Louri (2002) presentan estimaciones de eficiencia para la industria en Grecia. Sus resultados evidencian que las empresas con control mayoritariamente extranjero son las que se vinculan a niveles más elevados de productividad.
} 
En el contexto de países en desarrollo, Blomström y Sjöholm (1999) presentan evidencia similar para el caso de la industria manufacturera en Indonesia, donde las empresas transnacionales poseen mayor productividad laboral y las empresas locales también se benefician a través de derrames de productividad. Sin embargo, el grado de participación extranjera a nivel de empresas parece no tener relevancia en estos resultados. En América Latina, Blomström (1988) analiza la productividad laboral en la industria manufacturera de México. Sus resultados revelan que las subsidiarias de empresas transnacionales tienen mayor productividad debido a ventajas específicas en términos de capacidades y conocimiento, es decir, ventajas de propiedad. En un análisis más reciente, Álvarez y Crespi (2007) examinan el caso de la industria chilena durante el período 1979-2000. Sus resultados permiten ver que las empresas transnacionales poseen mayor PTF y, más aún, son importantes agentes en términos de transferencias de tecnología; por tanto, favorecen el proceso de convergencia de productividad (catching up progress) por parte de las empresas locales.

Ahora bien, en materia de sobrevivencia en el mercado existen argumentos teóricos contrapuestos con respecto al desempeño de las empresas transnacionales. Por una parte, las subsidiarias de empresas transnacionales pueden tener mayor probabilidad de salida, debido a que —en caso de una crisis económica — la empresa subsidiaria puede trasladar o modificar operaciones entre diferentes localizaciones productivas a través del sistema internacional de producción de la empresa transnacional. Esto puede resultar más evidente si la empresa subsidiaria tiene escasos encadenamientos con la economía local. Así, ante una crisis económica local, las subsidiarias de empresas transnacionales pueden ser más proclives a salir del mercado que las empresas locales. Por ejemplo, Bandick (2010) estudia el comportamiento en materia de sobrevivencia de las empresas transnacionales en la industria de Suecia. Los resultados sugieren que estas empresas tienen efectivamente mayor probabilidad de salida que las empresas locales. Sin embargo, al diferenciar según actividad exportadora, las empresas transnacionales tienen mayor sobrevivencia que las empresas locales no exportadoras, mientras que las tasas de sobrevivencia de las empresas transnacionales y de las exportadoras locales no son significativamente diferentes. De modo similar, Görg y Strobl (2003) y Bernard y Sjöholm (2003) muestran que las empresas transnacionales tienen mayor probabilidad de salida que las empresas domésticas en Irlanda e Indonesia, respectivamente. Para el caso chileno, Álvarez y Görg (2009) denotan que las subsidiarias de empresas transnacionales con orientación al mercado interno, durante la década de 1990, también tienen mayor probabilidad de salida del mercado que sus contrapartes locales.

Por otra parte, las subsidiarias de empresas transnacionales pueden presentar menos probabilidades de salida — es decir, mayor sobrevivencia — en la medida en que tienen mayores costos hundidos y proyectos de operación con retornos en el mediano plazo. Esto podría ser potencialmente relevante si se considera que una crisis económica es de carácter temporal. Si bien no existen estudios empíricos que confirmen este resultado, se ha mostrado que las empresas locales y transnacionales pueden comportarse de manera similar. En un estudio reciente, Godart, Görg y Hanley (2011) constatan que las empresas con diferente propiedad en Irlanda no registraron un comportamiento heterogéneo frente a la crisis económica de 2008. Es decir, si bien todas las empresas elevaron su tasa de salida en forma homogénea, las empresas transnacionales no fueron causa de mayor inestabilidad en la economía. Por su parte, Mata y Portugal (2002) resaltan que las empresas transnacionales y locales, luego de controlar por diferentes variables a nivel de empresa y de industria, poseen un comportamiento no muy distinto en materia de sobrevivencia en la industria de Portugal.

Finalmente, los estudios sobre diferencias en materia de rentabilidad entre empresas transnacionales y locales también son escasos y con resultados mixtos. Por una parte, en algunos estudios se aprecia que las ventajas de las empresas transnacionales se traducen efectivamente en mayores niveles de rentabilidad. Por ejemplo, Benvignati (1987) muestra que las empresas transnacionales en los Estados Unidos de América registran en promedio mayor rentabilidad que las empresas domésticas, siendo sus resultados estadísticamente robustos considerando diferentes medidas de capital extranjero en la propiedad. Kumar (1990), en tanto, analiza el sector manufacturero de la India. Sus resultados también sugieren que, en efecto, las empresas transnacionales tienen mejor desempeño que las empresas locales, y especialmente en sectores intensivos en conocimiento. Esto se debería a que dichos sectores pueden aprovechar su conocimiento y capacidades acumuladas, por ejemplo, a través de inversiones pasadas en actividades de investigación y desarrollo (I+D). Asimismo, Ramstteter (1998) examina la importancia de las empresas transnacionales en varias economías asiáticas. Sus resultados muestran, entre otras características, que las empresas transnacionales poseen mayores niveles de rentabilidad, por ejemplo en Singapur. Por el contrario, Barbosa y Louri (2005) 
estudian los casos de Portugal y Grecia en los años noventa. En el caso de Portugal, los resultados dejan ver que la propiedad extranjera no se vincula a diferencias significativas en materia de rentabilidad, pero sí en el caso de Grecia cuando se analizan los quintiles superiores de la distribución de rentabilidad.

\section{III}

\section{Datos y hechos estilizados}

Durante las últimas décadas, en la economía chilena se implementó un modelo de desarrollo basado en la apertura, la desregulación de los mercados y una fuerte predominancia del capital privado en las actividades productivas. En este contexto, la inversión extranjera directa (IED) se transformó también en una piedra angular de la estrategia de desarrollo y se estableció un marco legal con importantes garantías para el capital extranjero. De hecho, Chile destaca entre los países de América Latina como uno de los destinos más relevante de la IED en la última década, tanto en términos absolutos como en relación con el tamaño de su economía (CEPAL, 2012 y 2001) $)^{7}$. Las empresas transnacionales conformaron así un grupo de agentes con presencia en la mayoría de las actividades productivas y de servicios. De todas formas, hay que considerar que su presencia en el sector manufacturero es relativamente baja en comparación con la del sector primario o de servicios, que ha concentrado los mayores flujos de IED. Entre 2005 y 2010, el 92\% de la IED se dirigió a los sectores de recursos naturales y de servicios, mientras que solo el 7\% se destinó al sector manufacturero (CEPAL, 2012). Por su parte, entre 1996 y 2005, la participación del sector manufacturero en los flujos de IED en Chile fue mayor: en torno del 11\% (CEPAL, 2006).

Para analizar el desempeño de las empresas transnacionales en el sector manufacturero chileno se utiliza como fuente de información la Encuesta Nacional Industrial Anual (ENIA) respecto del período 2001-2006, proveniente del Instituto Nacional de Estadísticas (INE). En esta encuesta se recopila información a nivel de plantas industriales sobre producción, valor agregado, ventas, empleo, propiedad, salarios, exportaciones, inversiones y uso de energía, entre otras variables.

7 Durante el período 2000-2006, la IED promedio en Chile alcanzó a los 5.400 millones de dólares por año, mientras que en el período 2006-2011 superó los 15 mil millones de dólares. En los últimos años, el cuociente de IED sobre el producto interno bruto (PIB) ha superado el $8 \%$, uno de los más altos entre las mayores economías de América Latina (CEPAL, 2012).
Mediante deflactores sectoriales proporcionados por el INE, las variables monetarias fueron convertidas a pesos constantes de 2003. Para cada año, la encuesta recopila información sobre cerca de 4.500 plantas industriales, las que además son clasificadas a nivel de sectores según la Clasificación Industrial Internacional Uniforme de todas las actividades económicas (CIIU).

En la información proveniente de la ENIA se aprecia que las empresas transnacionales poseen una relativa baja predominancia en el empleo agregado, pero en cambio una participación bastante mayor en valor agregado, ventas y, especialmente, exportaciones. En 2006, las empresas manufactureras con capital extranjero representaban el $30 \%$ del valor agregado y el $45 \%$ de las exportaciones industriales, mientras que solo contribuían con el $17 \%$ del empleo (véase el gráfico 1). En relación con el inicio de la década, las empresas transnacionales mantuvieron o redujeron levemente su participación con respecto al empleo, el valor agregado y las ventas. Sin embargo, la aumentaron notablemente en relación con las exportaciones, desde un 34\% en 2001 al 45\% en 2006. Así, a medida que el país ha ido profundizando su inserción internacional, las transnacionales han adquirido mayor relevancia en materia de exportaciones, aprovechando probablemente sus mayores escalas de operación, su más avanzada tecnología y su mayor conocimiento de los mercados externos ${ }^{8}$.

Las características de los sectores productivos juegan un papel importante en el posicionamiento sectorial de las transnacionales. Aspectos relevantes son la intensidad de uso del capital, los costos hundidos, el óptimo tamaño de planta y los patrones tecnológicos de cada sector. De este modo, los sectores con mayor presencia relativa de empresas transnacionales, en términos de valor agregado, son las industrias del tabaco, el plástico, los metales no

\footnotetext{
8 Álvarez y López (2008) muestran que la actividad exportadora de las empresas transnacionales en el sector manufacturero de Chile genera importantes derrames de productividad, tanto hacia proveedores y clientes como a otras plantas en la misma industria.
} 
GRÁFICO 1

Chile: participación de las empresas transnacionales en el sector industrial (En porcentajes)

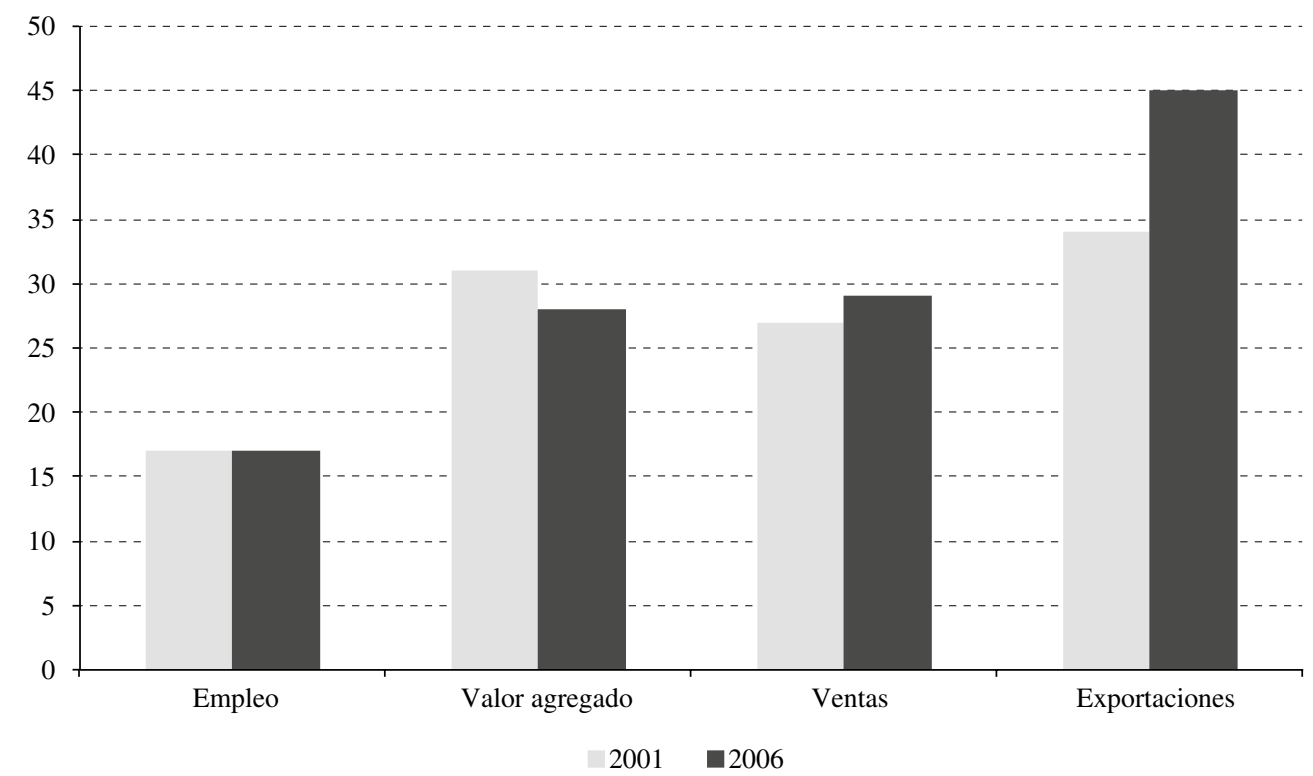

Fuente: elaboración propia sobre la base de la Encuesta Nacional Industrial Anual (ENIA), 2001-2006.

ferrosos, los equipos de transporte y de control científico y profesional. En estos sectores, la participación de las empresas con capital extranjero en el valor agregado sectorial supera el 50\%. Por el contrario, sectores con mayor uso de mano de obra registran una baja presencia de capital extranjero. Entre estos se destacan las industrias del cuero, los muebles, los textiles y las prendas de vestir. En estos sectores, la participación de las empresas transnacionales en el valor agregado sectorial no llega al $10 \%$.

A nivel más desagregado, las empresas transnacionales se distinguen de las empresas locales en diferentes aspectos. En el cuadro 1 se aprecia un panorama de algunas diferencias entre ambos grupos de empresas en la industria chilena. Se observa que las empresas manufactureras transnacionales son, en relación con las locales, significativamente más grandes, realizan en promedio mayores inversiones en capital físico y tienen, aunque levemente, mayor nivel de capacidades en sus empleados. A su vez, las empresas transnacionales están más orientadas a los mercados externos: en el período de análisis, más del $60 \%$ de las empresas transnacionales realizaron exportaciones en algún momento. Asimismo, mientras que las empresas locales que realizaron exportaciones destinaron en promedio solo el $6 \%$ de sus ventas a los mercados externos, esta cifra alcanzó al $28 \%$ en las empresas transnacionales.
En términos de desempeño, un ejercicio preliminar es observar los valores medios de la productividad laboral — definida como valor agregado sobre el número de empleados-, la sobrevivencia en el mercado y la rentabilidad según empresas. La productividad laboral es mayor en las empresas transnacionales, aspecto ampliamente documentado en la literatura, como se discutió en la sección anterior. Asimismo, la sobrevivencia es mayor en las empresas transnacionales con respecto a las locales, lo que resaltaría ventajas para sobrellevar de mejor manera las fluctuaciones del ciclo económico, por ejemplo, debido a las economías de escala y, probablemente, al acceso a financiamiento en mejores condiciones. Por último, las empresas transnacionales parecieran estar vinculadas a mayores niveles de rentabilidad. Para las empresas locales el índice de ingresos operacionales antes de impuestos, depreciaciones y amortizaciones sobre ventas es de un $24 \%$, mientras que para las transnacionales alcanza al 30\% (véase el cuadro 1).

De esta manera, el análisis descriptivo preliminar tiende a confirmar lo que a priori se espera del comportamiento de las empresas transnacionales en relación con las empresas locales: se trata de empresas más grandes, con mayor inversión en capital fijo y capacidad de sus empleados, y que en términos de desempeño poseen mayor productividad, sobrevivencia y rentabilidad. En la sección IV se analizan más profundamente estas diferencias. 


\begin{tabular}{|c|c|c|c|c|}
\hline \multirow[t]{2}{*}{ Variable } & \multicolumn{2}{|c|}{$\begin{array}{c}\text { Locales } \\
\text { (7 } 333 \text { empresas diferentes) } \\
(n=28871)\end{array}$} & \multicolumn{2}{|c|}{$\begin{array}{c}\text { Transnacionales } \\
\text { (549 empresas diferentes) } \\
(n=1950)\end{array}$} \\
\hline & Media & Desviación estándar & Media & Desviación estándar \\
\hline Tamaño & 66,54 & 144,9 & 208,77 & 343,8 \\
\hline Inversiones & 0,07 & 0,15 & 0,09 & 0,14 \\
\hline Exportaciones & 0,17 & 0,37 & 0,61 & 0,48 \\
\hline Orientación exportadora & 0,06 & 0,20 & 0,28 & 0,36 \\
\hline Productividad laboral & 9,02 & 1,09 & 10,37 & 1,38 \\
\hline Sobrevivencia & 0,89 & 0,30 & 0,92 & 0,26 \\
\hline EBITDA & 0,24 & 0,19 & 0,30 & 0,23 \\
\hline
\end{tabular}

Fuente: elaboración propia sobre la base de la Encuesta Nacional Industrial Anual (ENIA), 2001-2006.

Nota: variables explicativas: Tamaño: número de empleados. Inversiones: cuociente entre inversiones en capital físico y acervo de capital. Habilidades: cuociente entre número de empleados calificados y de empleados no calificados. Exportaciones: promedio de variable dicotómica que toma el valor 1 en caso de que la empresa sea exportadora, y 0 en caso contrario. Orientación exportadora: porcentaje de las ventas que realiza en el exterior. Productividad laboral: cuociente entre el valor agregado y número de empleados. Sobrevivencia: probabilidad de que la firma observada en el mercado en el período $t$ también lo sea en $t+1$. EBITDA: ingresos operacionales antes de intereses, impuestos, depreciaciones y amortizaciones como porcentaje de las ventas.

$n=$ número de empresas.

\section{IV}

\section{Estrategia empírica}

\section{Productividad}

El análisis de la productividad se realiza sobre la base de la productividad total de los factores (PTF). La PTF se calcula utilizando la metodología propuesta por Olley y Pakes (1996) y luego modificada por Levinsohn y Petrin (2003). Así, se estima una función de producción Cobb-Douglas para cada sector a tres dígitos de la CIIU a través de la siguiente ecuación:

$$
y_{i t}=\beta_{0}+\beta_{1} \mathrm{~K}_{i t}+\beta_{2} \mathrm{~L}^{s}{ }_{i t}+\beta_{3} \mathrm{~L}^{u}{ }_{i t}+\varepsilon_{i t}
$$

donde $y_{i t}$ es el logaritmo del valor agregado de la empresa $i$ a en el período $t ; \mathrm{K}_{\mathrm{it}}$ es el logaritmo del acervo de capital, mientras que $\mathrm{L}^{\mathrm{s}}$ it $\mathrm{y} \mathrm{L}_{\mathrm{it}}^{\mathrm{u}}$ corresponden a los logaritmos del número de trabajadores calificados y no calificados, respectivamente. La PTF se define luego como:

$$
P T F=\exp \left(y_{i t}-\beta_{1} \mathrm{~K}_{i t}-\beta_{2} \mathrm{~L}^{s}{ }_{i t}-\beta_{3} \mathrm{~L}^{u}{ }_{i t}\right)
$$

Si el error en la ecuación (1) no está correlacionado con las variables explicativas, la función de producción puede estimarse directamente mediante mínimos cuadrados ordinarios (MCO). Sin embargo, es usual esperar que el término de error $\varepsilon_{i t}$ esté correlacionado con las variables explicativas, ya que la productividad es observada por los gerentes de la firma, quienes toman además las decisiones respecto del uso de insumos en la producción. De acuerdo con los trabajos de Olley y Pakes (1996) y Levinsohn y Petrin (2003), se estima la función de producción considerando explícitamente este problema de endogeneidad. Para esto, se asume que $\varepsilon_{\text {it }}=\omega_{\text {it }}+\eta_{\text {it }}$, donde $\omega_{\text {it }}$ refleja la correlación con la productividad y que $\eta_{\text {it }}$ es un término de error que no está correlacionado con las decisiones de insumos productivos. Asimismo, se asume que $m_{\mathrm{it}}=m_{\mathrm{it}}\left(k_{i t}, \omega_{\mathrm{it}}\right)$, donde $m_{\text {it }}$ corresponde a los insumos intermedios usados en el proceso productivo. Levinsohn y Petrin (2003) muestran que esta relación es monotónicamente creciente en $\omega_{i t}$, de modo que la función de insumos intermedios puede ser invertida para obtener $\omega_{\mathrm{it}}=m_{\mathrm{it}}\left(k_{i t}, m_{\mathrm{it}}\right)$. Así, la función de producción a estimar queda especificada de la siguiente manera: 


$$
\begin{aligned}
& y_{i t}=\Phi\left(K_{i t}, m_{i t}\right)+\beta_{2} L_{i t}^{s}+\beta_{3} L_{i t}^{u}+\eta_{i t} \\
& \Phi\left(K_{i t}, m_{i t}\right)=\beta_{0} \beta_{1} K_{i t}+m_{i t}\left(K_{i t}, m_{i t}\right)
\end{aligned}
$$

La ecuación (3) se estima utilizando el consumo de electricidad como insumo intermedio y por tanto permite la identificación de la elasticidad del capital, corrigiendo el sesgo de simultaneidad. Una vez estimada la PTF para cada empresa y para los diferentes años del período de análisis, se emplea una prueba de medias (o de varianzas heterogéneas entre grupos de empresas) y la prueba de Kolmogorov-Smirnov para analizar si las distribuciones de la productividad según empresas, tanto en niveles como en diferencias, son similares. De igual modo, para analizar estas hipótesis se especifica el siguiente modelo de regresión en niveles y en diferencias:

$$
\begin{gathered}
P T F_{i t}=\theta X_{i t}+d_{j}+d_{t}+\varepsilon_{i j t} \\
\Delta P T F_{i t}=\theta X_{i t}+d_{j}+d_{t}+\varepsilon_{i j t}
\end{gathered}
$$

El vector de variables $X$ se compone de diferentes variables explicativas: tamaño de la empresa (número de empleados); inversiones (cuociente entre inversiones en capital fijo y acervo de capital); y habilidades del capital humano (cuociente entre número de empleados calificados y no calificados). Asimismo, se incluyen dos variables dicotómicas que controlan por la condición de empresa transnacional y la condición de empresa exportadora9 ${ }^{9}$. A priori, estas variables pueden afectar a la productividad tanto en niveles como en diferencias. Por su parte, las variables $\mathrm{d}_{\mathrm{j}} \mathrm{y}_{\mathrm{t}}$ son variables dicotómicas que controlan por efectos específicos a nivel de sectores (3 dígitos de CIIU) y por año, respectivamente. La estimación de las ecuaciones (5) y (6) se realiza por medio de $\mathrm{MCO}^{10}$.

\footnotetext{
9 En algunos estudios se muestra que el origen del capital también es relevante en las operaciones de las empresas transnacionales en terceros países. Por ejemplo, Crespi, Criscuolo y Haskel (2006) analizan el desempeño de empresas en el Reino Unido de Gran Bretaña e Irlanda del Norte y muestran que las multinacionales estadounidenses tienen prácticas de organización del trabajo y de uso de tecnologías de información que las hacen más flexibles y por ende más productivas que sus contrapartes europeas. Lamentablemente, la información según país de origen del capital extranjero no se encuentra disponible en la Encuesta Nacional Industrial Anual (ENIA) de Chile.

10 En el cuadro A.1 se presenta la matriz de correlaciones de las variables explicativas utilizadas en las estimaciones.
}

\section{Sobrevivencia}

Para analizar los patrones de sobrevivencia, y en particular la influencia del capital extranjero, se estima el siguiente modelo Probit:

$\operatorname{Pr}\left(\right.$ sobrevivencia $\left._{i j t}\right)=f\left(\alpha+\beta X_{i t}+\gamma Z_{j t}+d_{j}+d_{t}+\varepsilon_{i j t}\right)$

donde Pr (sobrevivencia $\mathrm{ijt}_{\mathrm{j}}$ ) es la probabilidad de sobrevivencia de la empresa $i$ que opera en el sector $j$ en el período $t ; \mathrm{X}_{\mathrm{it}}$ es un vector de variables que controlan diversas características de la empresa; y $\mathrm{Z}_{\mathrm{jt}}$ es un vector de variables que controlan por características a nivel de sectores industriales. Del mismo modo, $d_{j} y$ $\mathrm{d}_{\mathrm{t}}$ son variables dicotómicas que controlan por efectos específicos a nivel de sectores (3 dígitos de la CIIU) y a nivel de períodos, respectivamente. En concordancia con la literatura vinculada a sobrevivencia de empresas (Audretsch y Mahmood, 1995; Doms, Dunne y Roberts, 1995; Bernard y Sjoholm, 2003), en el vector de variables $\mathrm{X}$ se incluyen variables específicas a nivel de firma que a priori se espera que afecten a la sobrevivencia de la empresa. De esta manera, se incorporan como variables el tamaño de la empresa (número de empleados), la productividad (utilizando la medida de la PTF), las inversiones (inversiones en capital fijo sobre acervo de capital), y las habilidades del capital humano (cuociente entre número de empleados calificados y no calificados).

Además, se incluye una variable dicotómica que controla la propiedad extranjera de la empresa. Esta variable testea la hipótesis sobre la correlación que tiene la propiedad extranjera en la probabilidad de sobrevivencia de las empresas. Por una parte, las empresas transnacionales pueden tener ventajas relacionadas con mayor conocimiento y tecnología, y también mayores costos hundidos, lo que podría reducir la salida del mercado especialmente ante una perturbación temporal. Por el contrario, puede suceder que las empresas transnacionales tengan escaso conocimiento del mercado local y también obtengan provecho de redes internacionales de producción. Así, en caso de dificultades, estas empresas pueden decidir salir del mercado rápidamente y trasladar operaciones a otras localizaciones productivas. En ese sentido, las empresas transnacionales pueden ser especialmente sensibles a rentabilidades de corto plazo y tener un comportamiento de carácter footloose ${ }^{11}$.

\footnotetext{
11 Con la expresión "comportamiento footloose" se intenta caracterizar a aquellas empresas con propensión a relocalizar en forma geográfica sus operaciones productivas, como una respuesta estratégica en su posicionamiento a nivel internacional.
} 
También se podría argumentar que el grado de movilidad de las empresas transnacionales depende del nivel de activos intangibles que han invertido en su operación local (costos hundidos). De este modo, el grado de sobrevivencia podría ser diferente en sectores intensivos en conocimiento en comparación con sectores más tradicionales, como aquellos basados en recursos naturales o en mano de obra. Para testear la hipótesis de que las empresas transnacionales pueden tener diferente sobrevivencia según el tipo de sector donde operan, en las estimaciones también se incluyen variables dicotómicas que controlan por sectores intensivos en mano obra, recursos naturales y conocimiento ${ }^{12}$. La correlación que tenga la propiedad extranjera en la sobrevivencia de la empresa según diferentes sectores de operación se realiza aprovechando la no linealidad del modelo Probit.

Por su parte, en el vector $Z_{\mathrm{jt}}$ se incorporan 3 variables que controlan por características de la estructura de mercado a nivel de sectores. Así, se incluyen como variables explicativas el tamaño medio de firma y el índice de Herfindahl-Hirschman de concentración de mercado, las que están calculadas a un nivel de desagregación de 3 dígitos de la clasificación CIIU. En la tradición de los modelos de dinámica industrial, estas variables captan los diferentes costos de entrada según sectores industriales. Finalmente, como variable proxy para captar potenciales choques de demanda, se incluye el crecimiento de las ventas a nivel sectorial, también a 3 dígitos de la clasificación cirU. El modelo Probit se estima utilizando máxima verosimilitud.

\section{Rentabilidad}

El análisis de rentabilidad se realiza sobre la base de la siguiente ecuación empírica:

$$
E_{b i t d a_{i j t}}=\alpha+\beta X_{i t}+\gamma Z_{j t}+d_{j}+d_{t}+\varepsilon_{i j t}
$$

donde $E_{b i t d} a_{\mathrm{ijt}}=$ EBITDA $_{i j t}-$ EBITDA $_{j t}$, y EBITDA $_{i t}$ corresponde a ingresos operacionales antes de intereses, impuestos, depreciaciones y amortizaciones sobre ventas, para la empresa $i$ que opera en el sector $j$ en el período $t$; y EBITDA $_{\mathrm{jt}}$ es el promedio de esa variable para las empresas que operan en el sector $j$ en el período $t$. De esta manera, la variable Ebitda representa la desviación con respecto a la media sectorial de la rentabilidad de

12 La clasificación de sectores intensivos en recursos naturales, mano de obra y conocimiento se realizó teniendo en consideración la tipología discutida en Cimoli y otros (2005). cada empresa. Existen diferentes razones para utilizar esta variable en vez de emplear directamente la variable EBITDA, como por ejemplo, eliminar los diferentes niveles de rentabilidad entre industria y eliminar efectos comunes a todas las empresas, como por ejemplo, el ciclo económico ${ }^{13}$.

De acuerdo con la literatura previa, en el modelo de rentabilidad se utilizan como variables explicativas diferentes aspectos tanto a nivel de empresas como de sectores. De esta manera, se incluyen como variables el tamaño de la empresa, el cuociente entre inversiones y capital, las habilidades del capital humano y la condición de empresa exportadora. Con el objetivo de testear el efecto de la propiedad, se emplea una variable dicotómica que adquiere el valor 1 en caso de que la empresa tenga propiedad extranjera. Finalmente, se incorporan como variables de control la concentración del sector a través del índice de Herfindahl-Hirschman y el crecimiento de las ventas a nivel sectorial como variable proxy de choques de demanda.

La estimación empírica de la ecuación (8) se realiza a través de regresiones por cuantiles ${ }^{14}$. Al contrario de la estimación mediante MCO, en la regresión por cuantiles se estima la relación existente entre las variables en distintos cuantiles de la distribución de la variable dependiente (Koenker, 2005). Esta metodología tiene la ventaja de ser más robusta estadísticamente a valores extremos y en casos en que los errores no son normales. Así, dicha metodología permite ajustar regresiones para distintos cuantiles en la distribución de la rentabilidad de las empresas, lo que es especialmente relevante en situaciones de alta heterogeneidad muestral. De hecho - en estos casos - considerar la función condicional de la media, como ocurre en las estimaciones tradicionales mediante MCO, puede potencialmente ocultar aspectos significativos de la relación entre la variable dependiente y las variables explicativas. Así, se puede esperar que el capital extranjero tenga efectos heterogéneos en diferentes puntos de la distribución de rentabilidad ${ }^{15}$.

13 Para una discusión más detallada sobre este aspecto, véase Cefis y Cicarelli (2005).

14 En el modelo empírico se asume que la propiedad es exógena a la rentabilidad. Si bien en períodos largos se podría esperar que la rentabilidad incidiera en la presencia de capital extranjero, en el caso de un lapso de 6 años es poco probable. Además, solo un 2,9\% de las empresas cambiaron de propiedad durante el período.

15 Otro estudio en que se utilizan regresiones cuantílicas para analizar la rentabilidad de empresas es el de Love, Roper y Du (2009) en el caso de Irlanda. Si bien en el eje central de este artículo se hace referencia al efecto de la innovación en la rentabilidad, los resultados también muestran que las empresas transnacionales de los Estados Unidos de América y el Reino Unido tienen mayores niveles de rentabilidad que las empresas locales. 


\section{V}

\section{Resultados}

\section{Productividad}

En términos de productividad, se analiza la PTF tanto en niveles como en diferencias por medio de evidencia no paramétrica y paramétrica. La evidencia no paramétrica se basa en una prueba de medias (de varianzas heterogéneas entre grupos de empresas) y comparación de las distribuciones mediante la prueba de KolmogorovSmirnov (véase el cuadro 2) ${ }^{16}$. La prueba de medias muestra que las empresas transnacionales tienen un nivel de rentabilidad mayor que las empresas domésticas, siendo la diferencia estadísticamente significativa. Este resultado es consistente si se utiliza como criterio el tener algún grado de participación extranjera o sobre el 50\% de propiedad extranjera. En concordancia con lo anterior, la prueba de Kolmogorov-Smirnov pone de manifiesto que las productividades de ambos grupos de empresas provienen de diferentes distribuciones muestrales. De esta manera, una primera caracterización de la PTF entre empresas permite constatar que la propiedad extranjera es un elemento relevante.

16 En el gráfico A.1 se presenta el histograma de la PTF según tipo de empresas.
Asimismo, el análisis estadístico hace posible observar que no existen diferencias significativas en términos del crecimiento de la PTF. En consecuencia, no es posible rechazar la hipótesis de que la tasa de crecimiento promedio de la PTF sea diferente entre ambos grupos de empresas. Más aún, la tasa promedio anual de crecimiento de la productividad es mayor para las empresas domésticas $(1,6 \%)$ en comparación con las transnacionales $(0,7 \%)$. Esto revela que, si bien las transnacionales registran niveles de productividad más elevados, en las empresas locales la productividad presenta un mayor crecimiento. Sin embargo, es importante controlar por otras variables para comprobar que estas características se mantienen al considerar también tanto variables a nivel de firma como a nivel de sectores.

En el cuadro 3 se muestran las regresiones de las ecuaciones de productividad en niveles y diferencias a través de $\mathrm{MCO}^{17}$. En las columnas (1) y (2) se presentan

17 Las ecuaciones de productividad también podrían estimarse utilizando regresiones cuantílicas, en forma similar a las ecuaciones de rentabilidad. Sin embargo, en la implementación empírica, los resultados de las estimaciones cuantílicas muestran que no existen diferencias respecto de las estimaciones mediante MCO. Es decir, las estimaciones en los diferentes cuantiles de la distribución de productividad no son diferentes de la estimación por medio de MCO.

CUADRO 2

Chile: prueba sobre productividad total de los factores (PTF) entre empresas

\begin{tabular}{|c|c|c|}
\hline Variable & $\begin{array}{c}\text { Prueba de } \\
\text { Kolmogorov }- \text { Smirnov } \\
\mathrm{H}_{0} \text { : observaciones provienen } \\
\text { de la misma distribución }\end{array}$ & $\begin{array}{c}\text { Prueba de medias } \\
\mathrm{H}_{0}: \mathrm{PTF}_{\text {transnacionales }}=\mathrm{PTF}_{\text {domésticas }} \\
\mathrm{H}_{1}: \mathrm{PTF}_{\text {transnacionales }}>\mathrm{PTF}_{\text {domésticas }}\end{array}$ \\
\hline \multicolumn{3}{|c|}{$\begin{array}{l}\text { I. Empresas con capital extranjero en comparación } \\
\text { con empresas domésticas }\end{array}$} \\
\hline Productividad total de los factores (PTF) & $\begin{array}{l}0,380 \\
(0,000)^{* * *}\end{array}$ & $\begin{array}{l}28,83 \\
(0,000)^{* * * *}\end{array}$ \\
\hline$\Delta$ Productividad total de los factores (PTF) & $\begin{array}{l}0,048 \\
(0,006)^{* *}\end{array}$ & $\begin{array}{l}-0,405 \\
(0,657)\end{array}$ \\
\hline \multicolumn{3}{|c|}{$\begin{array}{l}\text { II. Empresas con al menos } 50 \% \text { de capital extranjero } \\
\text { comparadas con empresas domésticas }\end{array}$} \\
\hline Productividad total de los factores (PTF) & $\begin{array}{l}0,371 \\
(0,000) * * *\end{array}$ & $\begin{array}{l}24,66 \\
(0,000)^{* * *}\end{array}$ \\
\hline$\Delta$ Productividad total de los factores (PTF) & $\begin{array}{c}0,036 \\
(0,142)\end{array}$ & $\begin{array}{c}0,071 \\
(0,523)\end{array}$ \\
\hline
\end{tabular}

Fuente: elaboración propia sobre la base de la Encuesta Nacional Industrial Anual (ENIA), 2001-2006.

Nota: $* *$ significativo al $5 \%$; *** significativo al $1 \%$. 
CUADRO 3

Chile: estimaciones de productividad total de los factores (PTF)

\begin{tabular}{|c|c|c|c|c|}
\hline Variable & $\begin{array}{l}\text { Niveles } \\
\text { (1) }\end{array}$ & $\begin{array}{l}\text { Niveles } \\
\text { (2) }\end{array}$ & $\begin{array}{c}\text { Diferencias } \\
\text { (3) }\end{array}$ & $\begin{array}{c}\text { Diferencias } \\
\text { (4) }\end{array}$ \\
\hline \multirow[t]{2}{*}{ Tamaño } & 0,249 & 0,268 & $-0,010$ & $-0,012$ \\
\hline & $(25,62) * * *$ & $(33,16) * * *$ & $(-2,09)^{* *}$ & $(-2,52)^{* *}$ \\
\hline \multirow[t]{2}{*}{ Inversiones } & 0,130 & 0,165 & 0,055 & 0,067 \\
\hline & $(4,44) * * *$ & $(5,87)^{* * *}$ & $(1,65)^{*}$ & $(2,08)^{* * *}$ \\
\hline \multirow[t]{2}{*}{ Habilidades } & $-0,033$ & $-0,039$ & $-0,032$ & $-0,031$ \\
\hline & $(1,58)$ & $(-1,99)^{* *}$ & $(-2,54)^{* *}$ & $(-1,95)^{*}$ \\
\hline \multirow[t]{2}{*}{ Exportaciones } & 0,208 & 0,184 & $-0,001$ & 0,001 \\
\hline & $(10,28)^{* * * *}$ & $(10,10) * * *$ & $(-0,14)$ & $(0,14)$ \\
\hline \multirow[t]{2}{*}{ Transnacional } & 0,382 & 0,316 & 0,010 & 0,031 \\
\hline & $(9,36)^{* * *}$ & $(8,94)^{* * *}$ & $(0,48)$ & $(1,36)$ \\
\hline Efectos específicos del sector & No & Sí & No & Sí \\
\hline Efectos específicos del año & No & Sí & No & Sí \\
\hline Prob. Wald $>\mathrm{Chi}^{2}$ & 0,000 & 0,000 & 0,03 & 0,000 \\
\hline $\mathrm{N}^{\mathrm{o}}$ de empresas & 7103 & 7103 & 6125 & 6125 \\
\hline $\mathrm{N}^{\mathrm{o}}$ de observaciones & 27869 & 27869 & 20589 & 20589 \\
\hline
\end{tabular}

Fuente: elaboración propia sobre la base de la Encuesta Nacional Industrial Anual (ENIA), 2001-2006.

Nota: la variable dependiente es calculada según la metodología de Levinsohn y Petrin (2003). Variables explicativas: Tamaño: logaritmo del número de empleados. Productividad: PTF calculada según la metodología de Levinsohn y Petrin (2003). Inversiones: cuociente entre inversiones en capital físico y acervo de capital. Habilidades: cuociente entre número de empleados calificados y de empleados no calificados. Exportaciones: promedio de variable dicotómica que toma el valor 1 en caso de que la empresa realice exportaciones, y 0 en caso contrario. Transnacional: variable dicotómica que toma el valor 1 en caso de que la empresa tenga capital extranjero, y 0 en caso contrario (en columnas (1) a (3) se considera cualquiera participación extranjera, mientras que en la columnas (4) se considera sobre el 50\%).

* Significativo al $10 \%$; ** significativo al $5 \%$; *** significativo al $1 \%$.

estimaciones del nivel de la PTF. Dado que la columna (2) controla por efectos a nivel de sectores - los que pueden ser potencialmente relevantes en cómo las empresas transnacionales se distribuyen en la industria- es el modelo empírico por el que se opta. La estimación revela que el tamaño de la empresa se vincula positivamente a la productividad, lo que muestra beneficios en materia de economías de escala. Asimismo, inversiones en capital fijo también se relacionan positivamente con la productividad. En tanto, las habilidades presentan un coeficiente negativo y significativo, resultado a priori contraintuitivo. Por su parte, consistente con la evidencia internacional (Wagner, 2007) y también en Chile (Álvarez y López, 2005), la condición de empresa exportadora también presenta una significativa correlación con la productividad.

El interés central, sin embargo, se focaliza en la variable que controla por capital extranjero. Las estimaciones del cuadro 3 sugieren que las empresas transnacionales tienen, efectivamente, mayores niveles de productividad, debiendo controlarse por otras de sus características por efectos específicos a nivel de sectores, lo que confirma la evidencia descriptiva previa. A su vez, en el modelo de la columna (4) se utiliza la tasa de crecimiento de la PTF. Los resultados muestran que las empresas de menor tamaño son las que presentan mayor crecimiento de la PTF. Igualmente, las inversiones en capital fijo se vinculan positivamente al crecimiento de la productividad. Esto podría deberse a que las inversiones en maquinaria y equipos pueden elevar el nivel de producción e involucrar otras mejoras simultáneas, incluso en otras áreas, como las organizacionales. En concordancia con la evidencia descriptiva, el coeficiente relacionado con la variable transnacional no es significativo. De esta manera, controlando por otras variables, no existen diferencias significativas en la tasa de crecimiento de la productividad entre empresas domésticas y transnacionales.

$\mathrm{El}$ hecho de que la productividad sea mayor en las empresas transnacionales, pero que el crecimiento de la productividad sea similar entre empresas sugiere que las empresas locales pueden beneficiarse de derrames de productividad, transferencias de tecnología y aprendizaje de nuevas prácticas (Álvarez y Crespi, 2007). Así, estos resultados resaltan implícitamente la potencial incidencia que pueden tener políticas destinadas a promover efectos de derrame tecnológico (spillovers), 
así como del espacio existente para que las empresas transnacionales realicen una modernización (upgrading) tecnológica de sus actividades.

\section{Sobrevivencia}

Los resultados del modelo Probit se observan en el cuadro 4. El modelo de estimación base se presenta en la columna (1), y luego se agregan secuencialmente otras variables de control en las estimaciones. El tamaño se vincula positivamente a la probabilidad de sobrevivencia de las empresas, así como también a la productividad e inversión en capital físico. Empresas más grandes, más productivas y con tasas de inversión más elevadas, tienen mayores probabilidades de sobrevivencia. Estos resultados son consistentes con otros estudios de sobrevivencia empresarial tanto para países desarrollados como en desarrollo, y también para el caso particular de Chile (Audretsch y Mahmood; 1995; Van Biesebroeck, 2005; Álvarez y Vergara, 2013).

No obstante, el principal interés radica en comparar el comportamiento según la propiedad de las empresas. De acuerdo con las estimaciones, no existen diferencias significativas entre empresas transnacionales y locales, siendo no significativos los coeficientes estimados en las columnas (2) y (3). Sin embargo, y como forma de testear la robustez de las estimaciones, en el cuadro 4 se presentan estimaciones similares en las columnas (4), (5) y (6), pero bajo el criterio de que las empresas tengan al menos un 50\% de capital extranjero. La utilización

CUADRO 4

Chile: sobrevivencia de empresas, modelos Probit - efectos marginales

\begin{tabular}{|c|c|c|c|c|c|c|}
\hline Variable & (1) & (2) & (3) & (4) & (5) & (6) \\
\hline Tamaño & $\begin{array}{c}0,018 \\
(8,48) * * *\end{array}$ & $\begin{array}{c}0,019 \\
(8,10)^{* * *}\end{array}$ & $\begin{array}{c}0,019 \\
(8,08)^{* * *}\end{array}$ & $\begin{array}{c}0,018 \\
(8,48)^{* * *}\end{array}$ & $\begin{array}{c}0,019 \\
(8,09)^{* * *}\end{array}$ & $\begin{array}{c}0,019 \\
(8,07)^{* * *}\end{array}$ \\
\hline Productividad & $\begin{array}{l}0,015 \\
(6,89)^{* * * *}\end{array}$ & $\begin{array}{l}0,016 \\
(7,06) * * *\end{array}$ & $\begin{array}{l}0,016 \\
(7,04) * * *\end{array}$ & $\begin{array}{l}0,015 \\
(6,89)^{* * * *}\end{array}$ & $\begin{array}{l}0,016 \\
(7,09) * * *\end{array}$ & $\begin{array}{c}0,015 \\
(7,08)^{* * *}\end{array}$ \\
\hline Inversiones & $\begin{array}{c}0,039 \\
(3,14)^{* *}\end{array}$ & $\begin{array}{c}0,039 \\
(3,13)^{* *}\end{array}$ & $\begin{array}{c}0,039 \\
(3,13)^{* *}\end{array}$ & $\begin{array}{c}0,039 \\
(3,14)^{* *}\end{array}$ & $\begin{array}{c}0,038 \\
(3,13)^{* *}\end{array}$ & $\begin{array}{c}0,039 \\
(3,14)^{* *}\end{array}$ \\
\hline Habilidades & $\begin{array}{c}-0,005 \\
(-0,80)\end{array}$ & $\begin{array}{c}-0,004 \\
(-0,70)\end{array}$ & $\begin{array}{c}-0,004 \\
(-0,68)\end{array}$ & $\begin{array}{c}-0,005 \\
(-0,80)\end{array}$ & $\begin{array}{c}-0,004 \\
(-0,68)\end{array}$ & $\begin{array}{c}-0,004 \\
(-0,67)\end{array}$ \\
\hline Exportaciones & $\begin{array}{l}-0,003 \\
(-0,54)\end{array}$ & $\begin{array}{l}-0,004 \\
(-0,55)\end{array}$ & $\begin{array}{l}-0,003 \\
(-0,55)\end{array}$ & $\begin{array}{l}-0,003 \\
(-0,48)\end{array}$ & $\begin{array}{c}-0,002 \\
(-0,48)\end{array}$ & $\begin{array}{c}-0,003 \\
(-0,49)\end{array}$ \\
\hline Transnacional & & $\begin{array}{l}-0,013 \\
(-1,41)\end{array}$ & $\begin{array}{l}-0,013 \\
(-1,42)\end{array}$ & & $\begin{array}{c}-0,019 \\
(-1,83)^{*}\end{array}$ & $\begin{array}{c}-0,019 \\
(-1,83)^{*}\end{array}$ \\
\hline Concentración & & & $\begin{array}{c}0,098 \\
(1,06)\end{array}$ & & & $\begin{array}{c}0,096 \\
(1,04)\end{array}$ \\
\hline Tamaño medio de la firma & & & $\begin{array}{c}0,029 \\
(0,75)\end{array}$ & & & $\begin{array}{c}0,029 \\
(0,75)\end{array}$ \\
\hline Crecimiento del sector & & & $\begin{array}{c}0,11 \\
(0,88)\end{array}$ & & & $\begin{array}{c}0,122 \\
(0,91)\end{array}$ \\
\hline Efectos específicos del sector & Sí & Sí & Sí & Sí & Sí & Sí \\
\hline Efectos específicos del año & Sí & Sí & Sí & Sí & Sí & Sí \\
\hline Prueba Wald Chi (36) & 470,7 & 473,6 & 474,3 & 470,7 & 473,8 & 474,3 \\
\hline Prob. Wald $>\mathrm{Chi}^{2}$ & 0,000 & 0,000 & 0,000 & 0,000 & 0,000 & 0,000 \\
\hline $\mathrm{N}^{\circ}$ de observaciones & 23322 & 23322 & 23322 & 23322 & 23222 & 23222 \\
\hline
\end{tabular}

Fuente: elaboración propia sobre la base de la Encuesta Nacional Industrial Anual (ENIA), 2001-2006.

Nota: la variable dependiente es igual a 1 en caso de que la empresa tenga operaciones en $t+1$, y 0 en caso contrario. Tamaño: logaritmo de número de empleados. Productividad: calculada según la metodología de Levinsohn y Petrin (2003). Inversiones: cuociente entre inversiones en capital físico y acervo de capital. Habilidades: cuociente entre el número de empleados calificados y de empleados no calificados. Exportaciones: promedio de variable dicotómica que toma valor 1 en caso de que la empresa sea exportadora, y 0 en caso contrario. Transnacional: variable dicotómica que toma valor 1 en caso de que la empresa tenga capital extranjero, y 0 en caso contrario (en columnas (1) a (3) se considera cualquier participación extranjera, mientras que en columnas (4) a (6) se considera sobre el 50\%). Concentración: índice de Herfindahl-Hirschman calculado sobre el valor bruto de producción por sector (3 dígitos de la CIIU) y año. Tamaño medio de firma: promedio del número de empleados según sector (3 dígitos de la CIIU) y año. Crecimiento del sector: variación del valor bruto de producción según sector (3 dígitos de la CIIU) y año. Todas las estimaciones incluyen efectos específicos a nivel de sectores y por año.

* Significativo al $10 \%$; ** significativo al $5 \%$; *** significativo al $1 \%$. 
de este criterio se justifica dado que muchas decisiones de administración y manejo estratégico, como son el mantenerse en un mercado, cambiar la estructura de producción o tomar la decisión de emisión de nueva deuda, dependen de contar o no con el 50\% de propiedad. En ese sentido, es posible que solo las empresas con al menos $50 \%$ de propiedad extranjera posean en su administración y comportamiento el carácter de una empresa transnacional.

En forma consistente con los resultados de las columnas previas, en las estimaciones de las columnas (4), (5) y (6) del cuadro 4 se confirman los resultados respecto de las variables tamaño, PTF e inversiones en capital. Sin embargo, el coeficiente vinculado a la variable capital extranjero es positivo, aunque significativo solo al $10 \%$, lo que muestra que las empresas con al menos $50 \%$ de propiedad extranjera tienen, en promedio y permaneciendo el resto constante, un $2 \%$ de mayor probabilidad de salir del mercado con respecto a las empresas locales. Si bien es un efecto modesto en términos de magnitud y solo significativo al $10 \%$, sugiere la existencia de un comportamiento de tipo más bien footloose de las empresas transnacionales con relación a las locales.

Aprovechando la no linealidad del modelo Probit, se analiza para qué tipo de empresas el efecto de la propiedad extranjera en la sobrevivencia es más relevante ${ }^{18}$. En el cuadro 5 se ilustra el efecto marginal del capital extranjero según niveles de productividad y tamaño

18 En un modelo Probit, los efectos marginales son una función del resto de las variables explicativas. Comúnmente, los efectos marginales se calculan utilizando el valor promedio de dichas variables. El efecto marginal corresponde a la expresión: $\partial \operatorname{Pr}(y=1) / \partial X_{k}=\phi\left(X^{\prime} \beta\right) \beta_{k}$.

CUADRO 5

Chile: efectos marginales del capital extranjero en sobrevivencia de empresas ${ }^{a}$

\begin{tabular}{ccc}
\hline \multicolumn{3}{c}{ Según tamaño de la empresa } \\
\hline Pequeña & Mediana & Grande \\
\hline$-0,022$ & $-0,012$ & $-0,008$ \\
$(-1,69)^{*}$ & $(-1,66)^{*}$ & $(-1,62)^{*}$ \\
\hline \multicolumn{3}{c}{ Según productividad de la empresa } \\
\hline Baja & Media & Alta \\
\hline$-0,033$ & $-0,014$ & $-0,004$ \\
$(-1,79)^{*}$ & $(-1,67)^{*}$ & $(-1,50)$ \\
\hline
\end{tabular}

Fuente: elaboración propia sobre la base de la Encuesta Nacional Industrial Anual (ENIA), 2001-2006.

a Efectos marginales calculados sobre la base de los resultados de la columna (6) del cuadro 4

Nota: * Significativo al $10 \%$. de las empresas. El efecto de la propiedad extranjera en empresas con al menos $50 \%$ de dicha propiedad es mayor en magnitud en las empresas pequeñas. Por su parte, el efecto marginal del capital extranjero según la productividad es significativo solo en empresas de productividad baja y media, no así en aquellas de alta productividad y que probablemente son exportadoras.

Finalmente, se testea si las características sectoriales donde operan las empresas transnacionales son relevantes para su probabilidad de sobrevivencia. En primer lugar, las estimaciones denotan que todas las empresas que operan en sectores intensivos en conocimiento parecen tener menos sobrevivencia en relación con empresas en otros sectores (véanse las columnas (1) y (3) del cuadro A.2). Sin embargo, esto pierde significancia al incluir efectos sectoriales a 3 dígitos de la CiIU, de modo que no es posible sacar conclusiones consistentes (véanse las columnas (2) y (4) del cuadro A.2). Ahora bien, respecto de si las empresas transnacionales tienen un comportamiento diferenciado dependiendo del sector donde operan, las estimaciones muestran que este no es el caso (véase el cuadro A.3). De hecho, el efecto marginal estimado para las empresas transnacionales (utilizando ambos criterios, algún porcentaje de capital extranjero y más del 50\% de capital extranjero) es similar entre sectores y confirma los resultados de las estimaciones previas: solo las empresas transnacionales con un porcentaje de propiedad extranjera superior al $50 \%$ tienen menos probabilidades de sobrevivencia (al 10\% de significancia), resultado que es homogéneo entre sectores. Esto muestra que las empresas transnacionales no tienen un comportamiento diferenciado, en términos de sobrevivencia, en los sectores intensivos en conocimiento.

En definitiva, las empresas de propiedad mayoritariamente extranjera, pequeñas y de baja productividad son las que evidencian una mayor probabilidad de salida del mercado con respecto a sus contrapartes locales, independientemente de los sectores donde operan. Esto podría deberse a que estas empresas pueden padecer más intensamente los vaivenes del ciclo económico local por desconocimiento del mercado, falta de encadenamientos y menos flexibilidad para ajustarse a condiciones de menor demanda. Este resultado es consistente con lo también presentado por Álvarez y Görg (2009) para la industria manufacturera en Chile, pero durante la década de 1990. Los autores muestran que son las empresas transnacionales orientadas al mercado interno las que tienen menores probabilidades de sobrevivencia. 


\section{Rentabilidad}

Las estimaciones de rentabilidad por medio de regresiones cuantílicas se presentan en los cuadros 6 y $7^{19}$. Tales estimaciones se justifican en este caso, ya que la rentabilidad y los residuos estimados de la ecuación (8) mediante MCO no tienen una distribución normal ${ }^{20}$. Los cuadros 6 y 7 solo se diferencian en el criterio utilizado para definir a una empresa transnacional: algún porcentaje de propiedad extranjera en el primer caso, y al menos el 50\% en el segundo. Además, se presentan a modo de comparación las estimaciones por medio de MCO.

Las estimaciones presentan algunos resultados consistentes. Entre estos se destacan la correlación

19 En el gráfico A.2 se presenta el histograma de la rentabilidad según tipo de empresas.

${ }^{20}$ La prueba rechaza la distribución normal tanto para la rentabilidad como para los residuos estimados de la ecuación (8) con una significancia del $1 \%$. positiva entre rentabilidad y las variables que controlan por tamaño e inversiones en capital. Existe amplia evidencia de que el tamaño es un determinante significativo de la rentabilidad, ya que suele estar vinculado a beneficios en ámbitos como las economías de escala y mejores condiciones de acceso al crédito. La correlación positiva con inversiones puede en tanto estar reflejando buenas perspectivas de negocio a corto plazo. Asimismo, en varios cuantiles se observa que las empresas exportadoras tienen niveles más elevados de rentabilidad, lo que podría reflejar tanto mayores capacidades en el interior de la empresa como menor vulnerabilidad ante vaivenes de la demanda local.

El objetivo central de esta subsección es analizar la correlación con la variable que controla por empresa transnacional. Preliminarmente, se observa una relación positiva entre rentabilidad y capital extranjero en las estimaciones mediante MCO. Sin embargo, es evidente que la estimación por medio de MCO no realiza un buen trabajo al calcular un efecto promedio para la muestra.

CUADRO 6

Regresión cuantílica de rentabilidad (1)

\begin{tabular}{|c|c|c|c|c|c|c|}
\hline \multirow{2}{*}{ Variable } & \multirow{2}{*}{ MCO } & \multicolumn{5}{|c|}{ Cuantiles } \\
\hline & & 0,1 & 0,25 & 0,5 & 0,75 & 0,9 \\
\hline \multirow[t]{2}{*}{ Tamaño } & 0,009 & 0,022 & 0,014 & 0,008 & 0,004 & $-0,001$ \\
\hline & $(7,93)^{* * *}$ & $(12,18)^{* * *}$ & $(11,80)$ & $(7,61)^{* * *}$ & $(3,03)^{* *}$ & $(-0,44)$ \\
\hline \multirow[t]{2}{*}{ Inversiones } & 0,023 & 0,017 & 0,033 & 0,026 & 0,023 & 0,003 \\
\hline & $(3,47)^{* *}$ & $(1,68)^{*}$ & $(4,72)^{* * * *}$ & $(4,11)^{* * * *}$ & $(2,91)^{* *}$ & $(0,29)$ \\
\hline \multirow[t]{2}{*}{ Habilidades } & 0,010 & 0,000 & 0,002 & 0,006 & 0,014 & 0,023 \\
\hline & $(2,90)^{* *}$ & $(0,03)$ & $(0,75)$ & $(1,78)^{*}$ & $(3,04)^{* *}$ & $(3,62)^{* * *}$ \\
\hline \multirow[t]{2}{*}{ Exportaciones } & 0,009 & $-0,011$ & 0,004 & 0,008 & 0,020 & 0,035 \\
\hline & $(2,76)^{* *}$ & $(-2,28)^{* * *}$ & $(-1,43)$ & $(2,58)^{*}$ & $(4,80)^{* * * *}$ & $(6,05)^{* * *}$ \\
\hline \multirow[t]{2}{*}{ Transnacional 1} & 0,011 & $-0,030$ & $-0,015$ & $-0,001$ & 0,029 & 0,058 \\
\hline & $(2,10)^{* *}$ & $(-4,14)^{* * *}$ & $(-2,95)^{* *}$ & $(-0,25)$ & $(4,88)^{* * *}$ & $(6,91)^{* * *}$ \\
\hline \multirow[t]{2}{*}{ Concentración } & 0,060 & $-0,036$ & 0,016 & 0,036 & 0,047 & 0,144 \\
\hline & $(1,17)$ & $(-0,50)$ & $(0,33)$ & $(0,74)$ & $(0,78)$ & $(1,71)^{*}$ \\
\hline \multirow[t]{2}{*}{ Crecimiento del sector } & 0,013 & 0,094 & $-0,011$ & 0,007 & 0,025 & 0,039 \\
\hline & $(1,42)$ & $(6,23)^{* * *}$ & $(-1,26)$ & $(0,71)$ & $(2,58) *$ & $(3,29)^{* *}$ \\
\hline Efectos específicos del sector & Sí & Sí & Sí & Sí & Sí & Sí \\
\hline Efectos específicos del año & Sí & Sí & Sí & Sí & Sí & Sí \\
\hline $\mathrm{N}^{\mathrm{o}}$ de observaciones & 28895 & 28895 & 28895 & 28895 & 28895 & 28895 \\
\hline
\end{tabular}

Fuente: elaboración propia sobre la base de la Encuesta Nacional Industrial Anual (ENIA), 2001-2006.

Nota: variable dependiente: $E b i t d a_{i j t}=$ EBITDA $_{i j t}-$ EBITDA $_{j t}$, donde EBITDA ${ }_{i t}$ corresponde a ingresos operacionales antes de intereses, impuestos, depreciaciones y amortizaciones sobre ventas, para la empresa $i$ que opera en el sector $j$ en el período $t$, y EBITDA $j t$ es el promedio de esa variable para las empresas que operan en el sector $j$ en el período $t$. Tamaño: logaritmo del número de empleados. Inversiones: cuociente entre inversiones en capital físico y acervo de capital. Habilidades: cuociente entre número de empleados calificados y de empleados no calificados. Exportaciones: promedio de variable dicotómica que toma el valor 1 en caso de que la empresa sea exportadora, y 0 en caso contrario. Transnacional 1: variable dicotómica que toma el valor 1 en caso de que la empresa tenga más del 50\% de capital extranjero, y 0 en caso contrario. Concentración: índice de Herfindahl-Hirschman calculado con el valor bruto de producción por sector (3 dígitos de la CIIU) y año. Crecimiento del sector: variación del valor bruto de producción según sector (3 dígitos de la ciIU) y año. Mco: mínimos cuadrados ordinarios.

* Significativo al $10 \%$; ** significativo al $5 \%$; *** significativo al $1 \%$. 
CUADRO 7

Regresión cuantílica de rentabilidad (2)

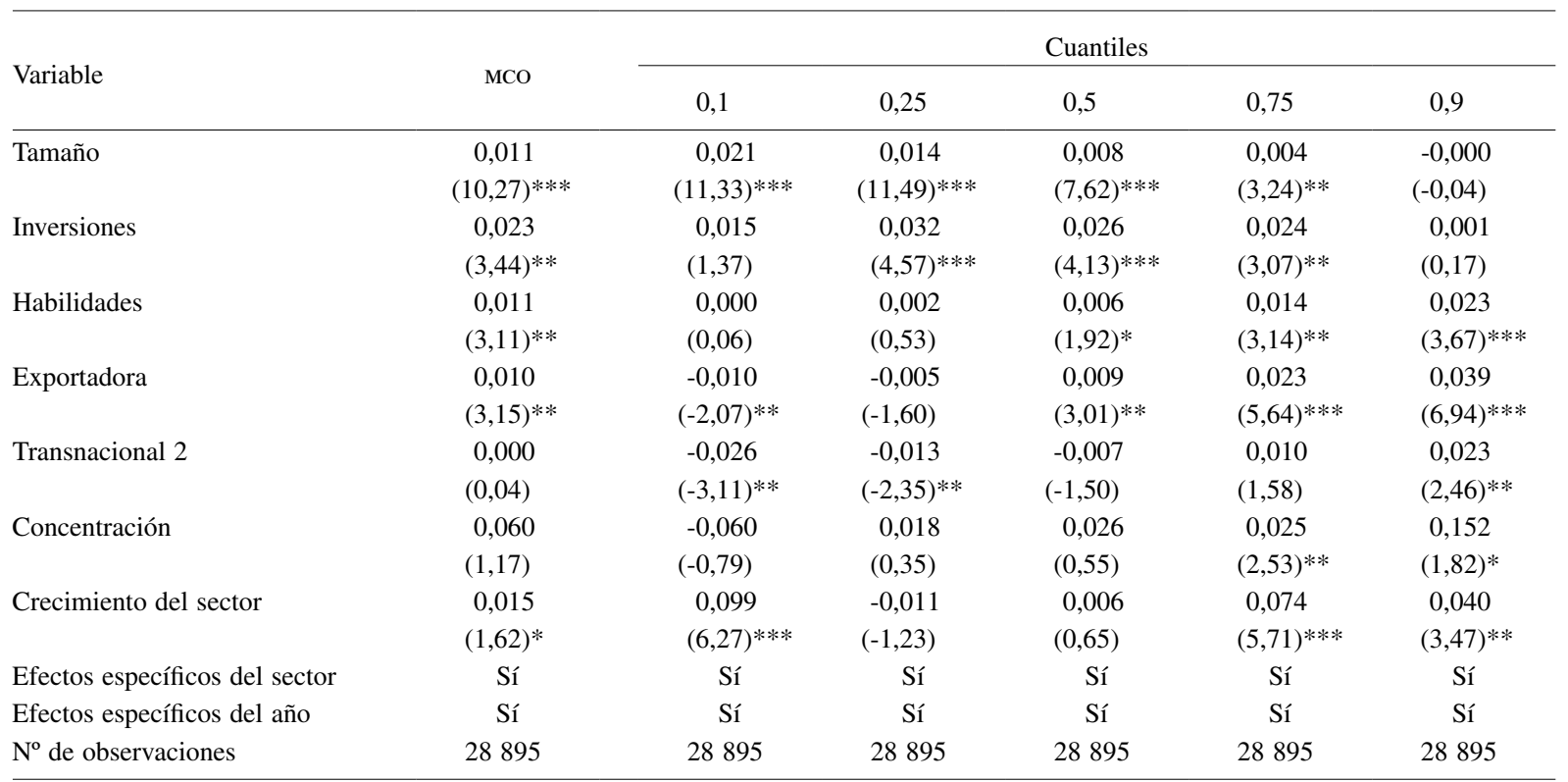

Fuente: elaboración propia sobre la base de la Encuesta Nacional Industrial Anual (ENIA), 2001-2006.

Nota: variable dependiente: $E_{b i t d a_{i j t}}=\mathrm{EBITDA}_{i j t}-\mathrm{EBITDA}_{j t}$, donde $\mathrm{EBITDA}_{i t}$ corresponde a ingresos operacionales antes de intereses, impuestos, depreciaciones y amortizaciones sobre ventas, para la empresa $i$ que opera en el sector $j$ en el período $t$, y EBITDA $j$ es el promedio de esa variable para las empresas que operan en el sector $j$ en el período $t$. Tamaño: logaritmo del número de empleados. Inversiones: cuociente entre inversiones en capital físico y acervo de capital. Habilidades: cuociente entre número de empleados calificados y de empleados no calificados. Exportaciones: promedio de variable dicotómica que toma el valor 1 en caso de que la empresa sea exportadora, y 0 en caso contrario. Transnacional 2: variable dicotómica que toma el valor 1 en caso de que la empresa tenga más del $50 \%$ de capital extranjero, y 0 en caso contrario. Concentración: índice de Herfindahl-Hirschman calculado con el valor bruto de producción por sector (3 dígitos de la CIIU) y año. Crecimiento del sector: variación del valor bruto de producción según sector (3 dígitos de la cirU) y año. MCo: mínimos cuadrados ordinarios.

* Significativo al $10 \%$; ** significativo al $5 \%$; *** significativo al $1 \%$.

Es así como las estimaciones cuantílicas proveen mayor información al mostrar un efecto heterogéneo en los diferentes puntos de la distribución de rentabilidad. En ambas estimaciones, es decir, al considerar ambos criterios de empresa transnacional, se aprecia que el coeficiente es negativo y significativo en los dos primeros cuantiles de la distribución de rentabilidad. Esto sugiere que, en situaciones de relativa baja rentabilidad empresarial, el capital extranjero parece vincularse en forma negativa al desempeño de las empresas. Así, las empresas transnacionales tienen menor rentabilidad que las empresas locales. Esto podría explicarse por el hecho de que las empresas transnacionales con bajos niveles de rentabilidad pueden adolecer más agudamente —en relación con empresas locales de un mismo sector-de un mayor desconocimiento del mercado, de menores encadenamientos productivos y de falta de flexibilidad y manejo estratégico para adecuarse a condiciones de más alta presión competitiva y cambios en los patrones de demanda. Por ejemplo, las empresas transnacionales pueden tener definida su estructura de productos sobre la base de criterios no exclusivamente locales. Este resultado es consistente con lo presentado en la sección anterior, donde se advierte que las transnacionales pequeñas y con menor productividad tienen mayores probabilidades de salir del mercado. Un aspecto importante que explicaría este hecho sería que estas empresas transnacionales presentan un menor nivel de rentabilidad con respecto a las empresas locales.

Del mismo modo, las estimaciones denotan que la propiedad extranjera se vincula en forma positiva y significativa a la rentabilidad en los dos cuantiles por sobre la media de la distribución de rentabilidad. Así, en situaciones de relativa alta tasa de utilidades, las empresas transnacionales tienen mejor desempeño en comparación con las empresas locales y pueden explotar ventajas en materia de economías de escala, patentes, licencias y tecnologías específicas, canales de distribución en el 
extranjero o condiciones de acceso a financiamiento. En estricto rigor, no es posible hablar de empresas de baja o alta rentabilidad en casos donde se implementa una regresión cuantílica en datos de panel. Sin embargo, dado que la desviación estándar de la rentabilidad intraempresa es la mitad de la desviación entre empresas, se puede asumir a grosso modo que las observaciones en los quintiles de alta rentabilidad se vinculan a empresas de alta rentabilidad, mientras que las observaciones en los quintiles bajos se relacionan con empresas de baja

\section{VI}

\section{Conclusiones}

En este artículo se analizó el desempeño de las empresas transnacionales en la industria manufacturera en el contexto de una economía pequeña y abierta como la chilena. Primero, los resultados permiten ver que las subsidiarias de empresas transnacionales tienen un desempeño distinto al de las empresas domésticas, y que este difiere también entre ellas según diferentes características, lo que resalta la heterogeneidad productiva en la industria manufacturera. Segundo, las empresas transnacionales tienen mayores niveles de productividad con respecto a las empresas locales, pero no así en términos de su crecimiento. En tercer lugar, los resultados evidencian que las empresas transnacionales y locales no presentan grandes diferencias en materia de sobrevivencia en el mercado. Sin embargo, un análisis más detallado también deja ver que las empresas de capital mayoritariamente extranjero, y sobre todo pequeñas y de baja productividad, muestran mayor probabilidad de salida del mercado con respecto a sus contrapartes locales. Esto se vincula a menores niveles de rentabilidad en los primeros cuantiles de la distribución. Probablemente, las subsidiarias de empresas transnacionales de baja productividad poseen poco conocimiento del mercado, menores encadenamientos y menos capacidad para ajustarse a vaivenes de la demanda interna. Por último, rentabilidad ${ }^{21}$. De este modo, se podría decir que entre empresas de alta rentabilidad, las transnacionales tienen mejor desempeño que las locales. Por el contrario, entre empresas de baja rentabilidad, son las empresas locales las que tienen mejor desempeño relativo.

\footnotetext{
${ }^{21}$ Estimaciones de la ecuación (8) —utilizando variables promedio a nivel de empresa (tanto para rentabilidad como para las variables explicativas - generan conclusiones similares.
}

los resultados ponen de manifiesto que la propiedad extranjera no se relaciona en forma lineal e inequívoca con la rentabilidad. Por ejemplo, las empresas transnacionales parecieran tener mayores niveles de rentabilidad que las empresas locales solo en los cuantiles superiores de la distribución de rentabilidad. Es decir, no es posible asumir que las empresas subsidiarias de transnacionales poseen en forma permanente y robusta mayores tasas de utilidad que las empresas locales.

En definitiva, en este artículo se discuten algunas de las particularidades que revisten las operaciones de las empresas transnacionales en Chile. Esto en un contexto de alta heterogeneidad, como es el sector manufacturero. Estos resultados, obviamente, no son extensivos a otros sectores de la producción, como recursos naturales o servicios, donde los patrones de competencia y las características de las subsidiarias de empresas transnacionales difieren significativamente de los de su presencia en el sector manufacturero. Considerar los patrones de desempeño de las empresas transnacionales es importante en el actual contexto de auge de flujos de inversión extranjera en la región, y especialmente a la hora de discutir políticas en el ámbito productivo y tecnológico tendientes a fortalecer sus beneficios en las economías receptoras. 
ANEXO

GRÁFICO A.1

Histograma de productividad total de los factores (PTF)

A. Empresas locales

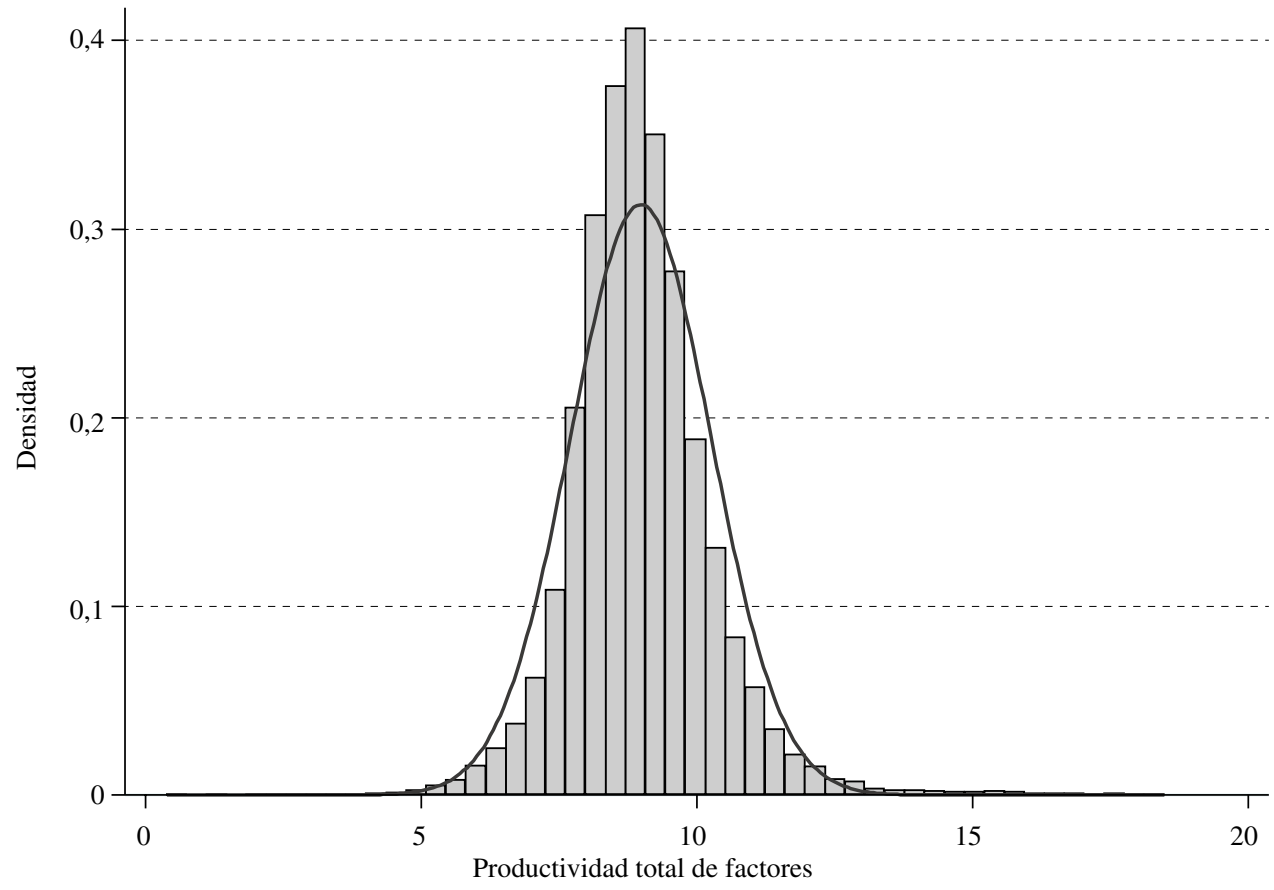

B. Empresas transnacionales

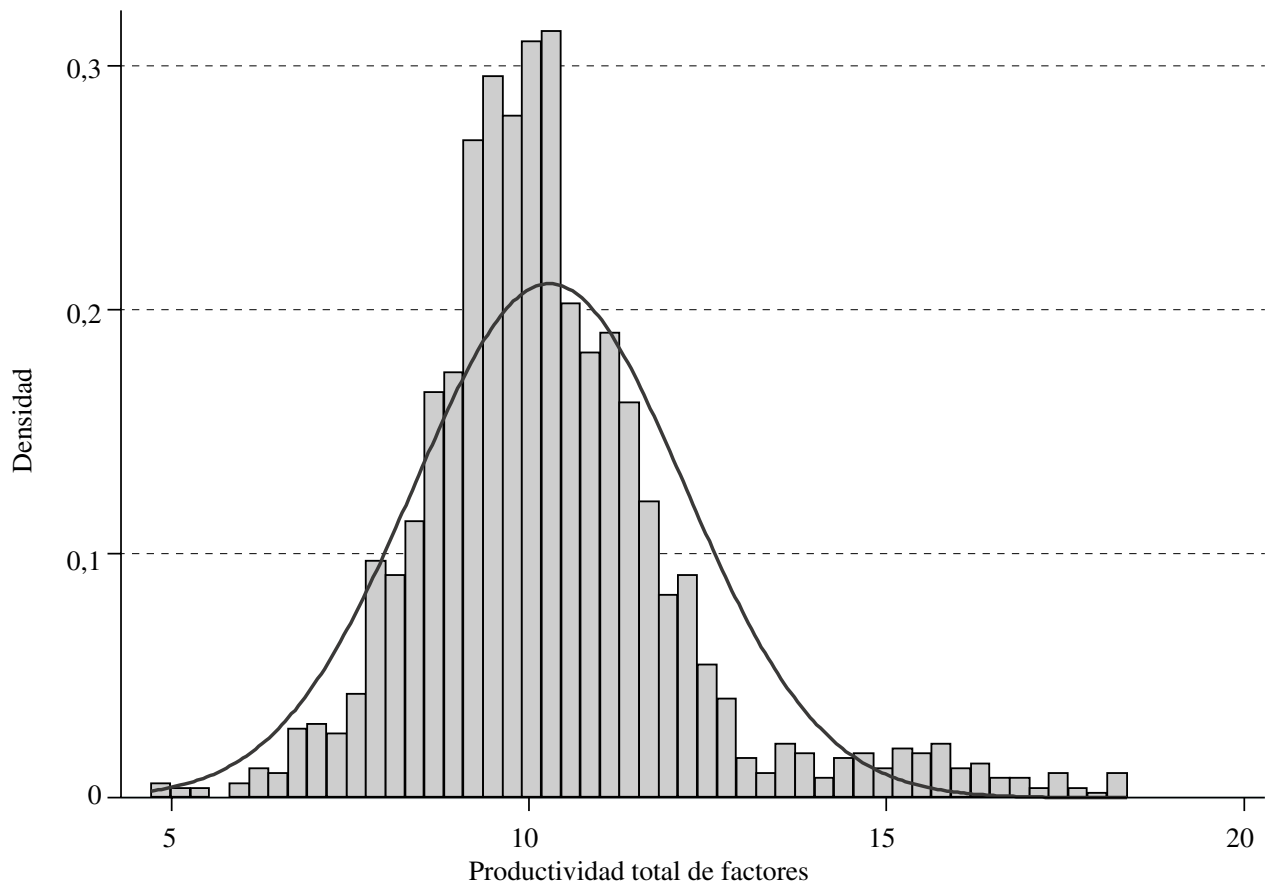

Fuente: elaboración propia sobre la base de la Encuesta Nacional Industrial Anual (ENIA), 2001-2006. 
GRÁFICO A.2

\section{Histograma de rentabilidad}

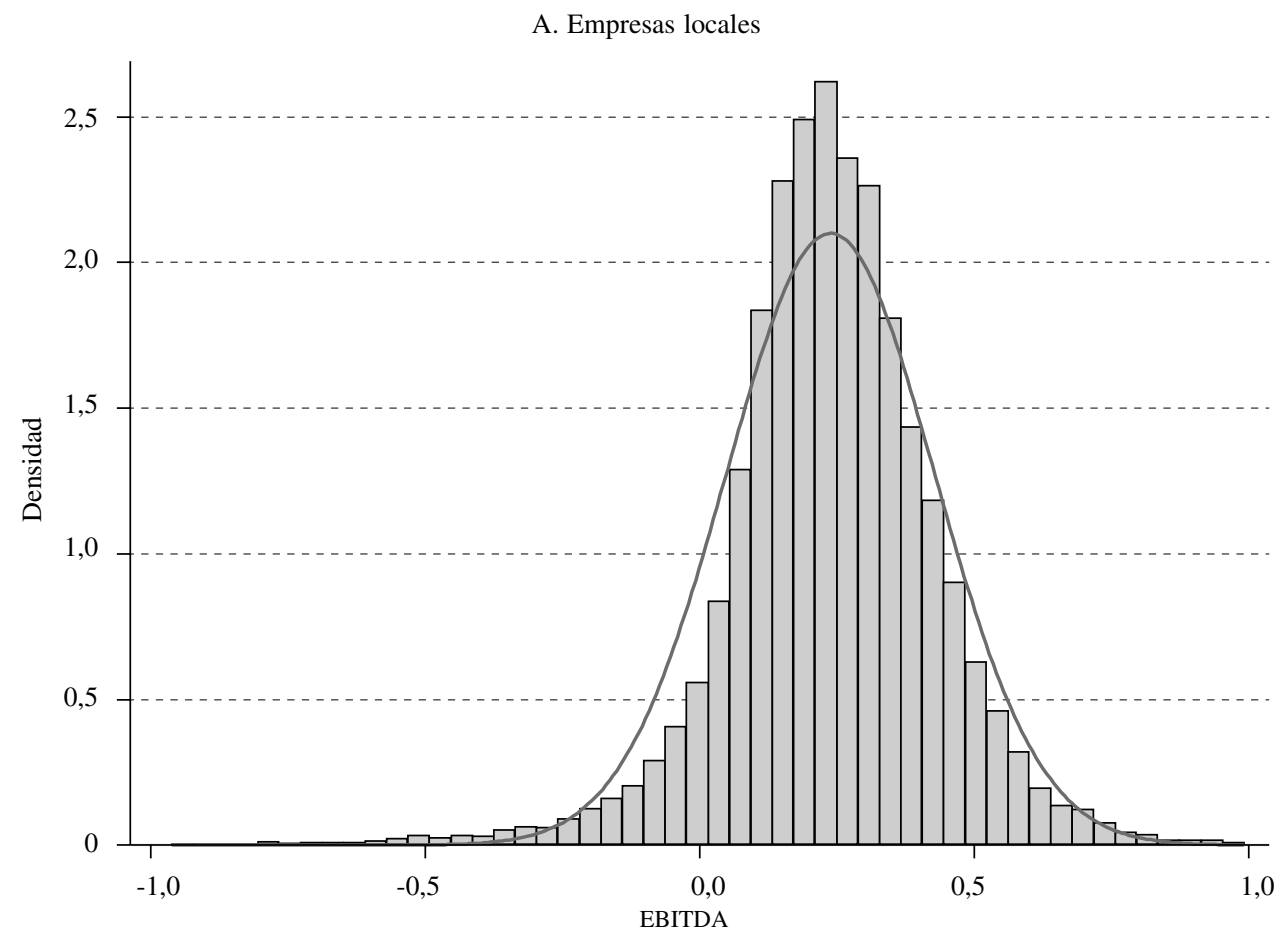

B. Empresas transnacionales

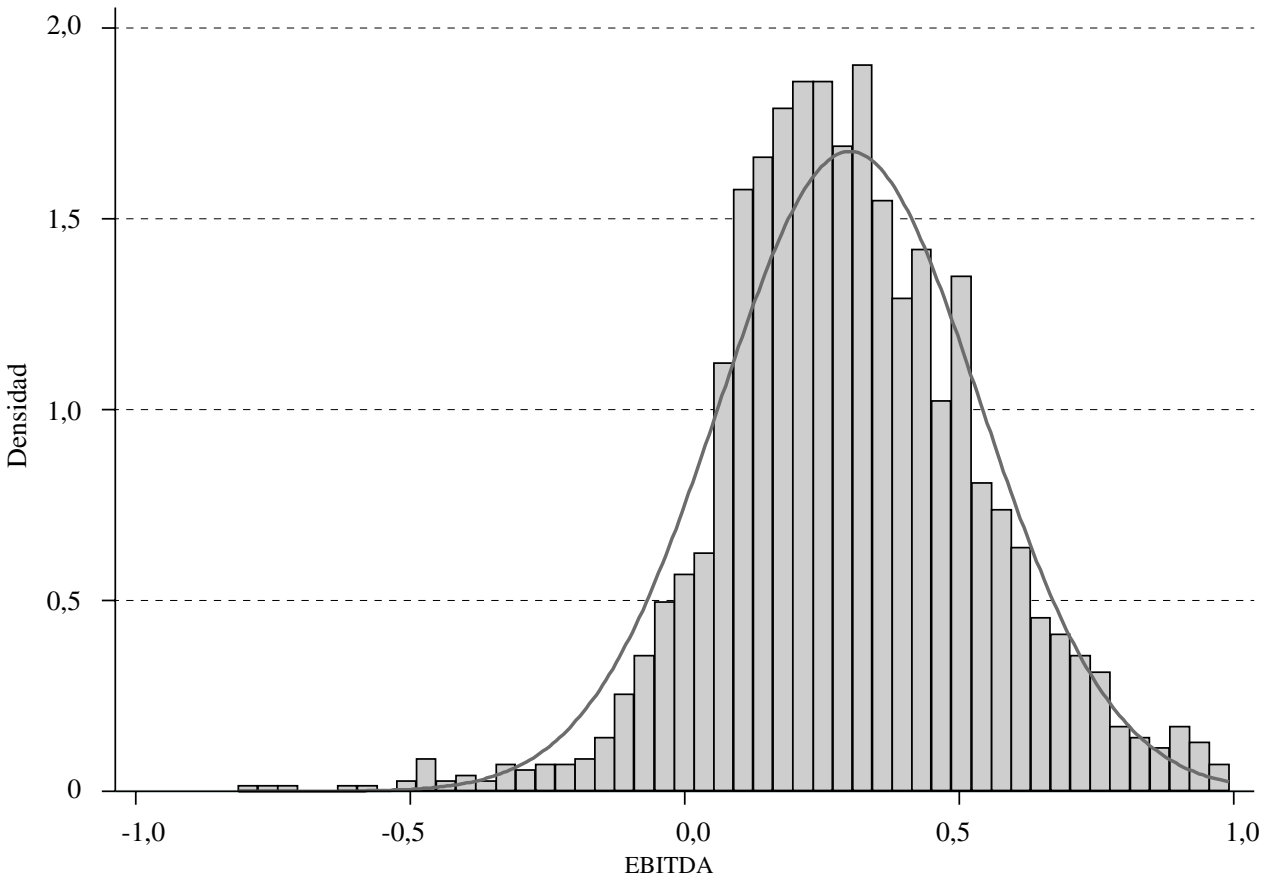

Fuente: elaboración propia sobre la base de la Encuesta Nacional Industrial Anual (ENIA), 2001-2006.

EBITDA: ingresos operacionales antes de intereses, impuestos, depreciaciones y amortizaciones sobre ventas. 


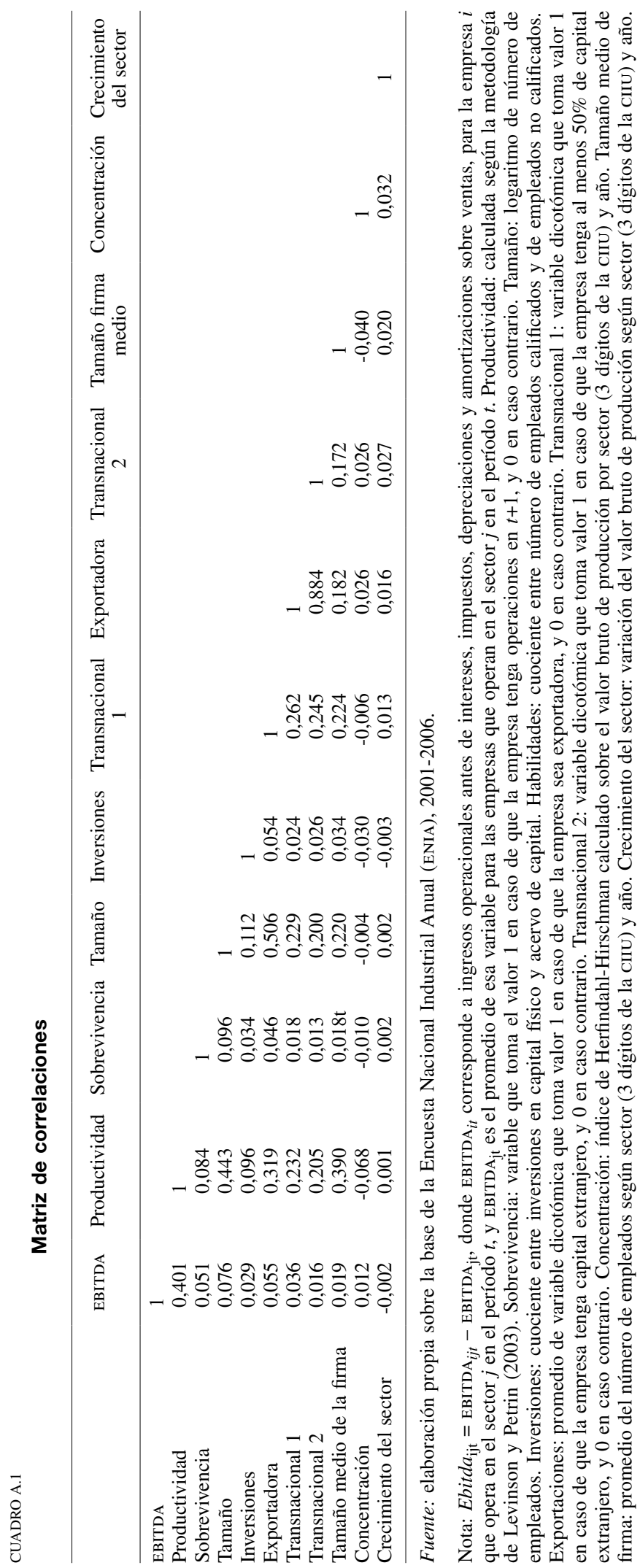


CUADRO A.2

Sobrevivencia de empresas, modelos Probit - efectos marginales

\begin{tabular}{|c|c|c|c|c|}
\hline Variable & (1) & (2) & (3) & $(4)$ \\
\hline Tamaño & $\begin{array}{l}0,019 \\
(8,11)^{* * *}\end{array}$ & $\begin{array}{l}0,019 \\
(7,91)^{* * *}\end{array}$ & $\begin{array}{l}0,019 \\
(8,10)^{* * *}\end{array}$ & $\begin{array}{c}0,019 \\
(7,90)^{* * *}\end{array}$ \\
\hline Productividad & $\begin{array}{c}0,015 \\
(7,79)^{* * *}\end{array}$ & $\begin{array}{c}0,015 \\
(6,96)^{* * *}\end{array}$ & $\begin{array}{l}0,015 \\
(7,84)^{* * *}\end{array}$ & $\begin{array}{c}0,015 \\
(7,00)^{* * *}\end{array}$ \\
\hline Inversiones & $\begin{array}{c}0,040 \\
(3,24)^{* *}\end{array}$ & $\begin{array}{c}0,039 \\
(3,13)^{* *}\end{array}$ & $\begin{array}{c}0,040 \\
(3,24)^{* *}\end{array}$ & $\begin{array}{c}0,039 \\
(3,13)^{* *}\end{array}$ \\
\hline Habilidades & $\begin{array}{l}-0,004 \\
(0,67)\end{array}$ & $\begin{array}{l}-0,004 \\
(0,66)\end{array}$ & $\begin{array}{l}-0,004 \\
(0,65)\end{array}$ & $\begin{array}{l}-0,004 \\
(0,64)\end{array}$ \\
\hline Exportaciones & $\begin{array}{l}-0,002 \\
(0,44)\end{array}$ & $\begin{array}{l}-0,003 \\
(0,65)\end{array}$ & $\begin{array}{l}-0,002 \\
(0,40)\end{array}$ & $\begin{array}{l}-0,003 \\
(0,59)\end{array}$ \\
\hline Transnacional & $\begin{array}{l}-0,009 \\
(1,07)\end{array}$ & $\begin{array}{l}-0,012 \\
(1,33)\end{array}$ & $\begin{array}{l}-0,014 \\
(1,46)\end{array}$ & $\begin{array}{l}-0,018 \\
(1,79)^{*}\end{array}$ \\
\hline Concentración & $\begin{array}{l}-0,008 \\
(0,35)\end{array}$ & $\begin{array}{c}0,099 \\
(1,07)\end{array}$ & $\begin{array}{l}-0,008 \\
(0,34)\end{array}$ & $\begin{array}{c}0,097 \\
(1,05)\end{array}$ \\
\hline Tamaño medio de la firma & $\begin{array}{l}-0,017 \\
(1,92)^{* *}\end{array}$ & $\begin{array}{c}0,029 \\
(0,75)\end{array}$ & $\begin{array}{l}-0,016 \\
(1,88)^{*}\end{array}$ & $\begin{array}{c}0,029 \\
(0,76)\end{array}$ \\
\hline Crecimiento del sector & $\begin{array}{c}0,118 \\
(0,86)\end{array}$ & $\begin{array}{c}0,114 \\
(0,87)\end{array}$ & $\begin{array}{c}0,121 \\
(0,88)\end{array}$ & $\begin{array}{c}0,119 \\
(0,89)\end{array}$ \\
\hline Dummy de recursos naturales & $\begin{array}{c}0,001 \\
(0,42)\end{array}$ & $\begin{array}{l}-0,020 \\
(0,97)\end{array}$ & $\begin{array}{c}0,002 \\
(0,46)\end{array}$ & $\begin{array}{l}-0,021 \\
(0,97)\end{array}$ \\
\hline Dummy de conocimiento & $\begin{array}{l}-0,016 \\
(2,75)^{* *}\end{array}$ & $\begin{array}{c}-0,011 \\
(0,39)\end{array}$ & $\begin{array}{l}-0,015 \\
(2,72)^{* *}\end{array}$ & $\begin{array}{c}-0,010 \\
0,35)\end{array}$ \\
\hline Efectos específicos sector & No & Sí & No & Sí \\
\hline Efectos específicos año & Sí & Sí & Sí & Sí \\
\hline Prueba Wald Chi (36) & 436,98 & 471,29 & 436,94 & 471,18 \\
\hline Prob. Wald $>\mathrm{Chi}^{2}$ & 0,000 & 0,000 & 0,000 & 0,000 \\
\hline $\mathrm{N}^{\mathrm{o}}$ de observaciones & 23322 & 23322 & 23322 & 23322 \\
\hline
\end{tabular}

Fuente: elaboración propia sobre la base de la Encuesta Nacional Industrial Anual (ENIA), 2001-2006.

Nota: la variable dependiente es igual a 1 en caso de que la empresa tenga operaciones en $t+1$, y 0 en caso contrario. Tamaño: logaritmo de número de empleados. Productividad: calculada según la metodología de Levinsohn y Petrin (2003). Inversiones: cuociente entre inversiones en capital físico y acervo de capital. Habilidades: cuociente entre número de empleados calificados y de empleados no calificados. Exportaciones: promedio de variable dicotómica que toma valor 1 en caso de que la empresa sea exportadora, y 0 en caso contrario. Transnacional: variable dicotómica que toma valor 1 en caso de que la empresa tenga capital extranjero, y 0 en caso contrario (en columnas (1) y (2) se considera cualquier participación extranjera, mientras que en columnas (3) y (4) se considera sobre el 50\%). Concentración: índice de HerfindahlHirschman calculado sobre el valor bruto de producción por sector (3 dígitos de la ciıU) y año. Tamaño medio de firma: promedio del número de empleados según sector (3 dígitos de la CIIU) y año. Crecimiento del sector: variación del valor bruto de producción según sector ( 3 dígitos de la CIIU) y año. Dummy de conocimiento: variable que toma valor 1 si la empresa opera en sectores intensivos en conocimiento y 0 en caso contrario. Dummy de recursos naturales: variable que toma valor 1 si la empresa opera en sectores intensivos en mano de obra y 0 en caso contrario. Todas las estimaciones incluyen efectos específicos a nivel de sectores y por año.

* Significativo al $10 \%$; ** significativo al $5 \%$; *** significativo al $1 \%$.

CUADRO A.3

Efectos marginales del capital extranjero en sobrevivencia de empresas ${ }^{a}$

Grado de capital extranjero

Sectores intensivos en conocimiento

Otros sectores

Transnacional 1

(algún porcentaje de propiedad extranjera)

Transnacional 2

$-0,012$

$(1,27)$

$-0,019$

$(1,65)^{*}$

$-0,013$
$(1,26)$

(al menos $50 \%$ de propiedad extranjera)

$-0,018$

$(1,67)^{*}$

Fuente: elaboración propia sobre la base de la Encuesta Nacional Industrial Anual (ENIA), 2001-2006.

a Efectos marginales calculados sobre la base de los resultados de las columnas (2) y (4) del cuadro A.2.

Nota: * Significativo al $10 \%$. 


\section{Bibliografía}

Álvarez, R. y G. Crespi (2007), "Multinational firms and productivity catching-up: the case of Chilean manufacturing", International Journal of Technological Learning, Innovation and Development, vol. 1, $\mathrm{N}^{\circ}$ 2, Inderscience Enterprises Ltd., enero.

Álvarez, R. y H. Görg (2009), "Multinationals and plant exit: evidence from Chile", International Review of Economics and Finance, vol. 18, $\mathrm{N}^{\circ} 1$, Amsterdam, Elsevier.

Álvarez, R. y R. López (2008), "Is exporting a source of productivity spillovers?", Review of World Economics, vol. 144, $\mathrm{N}^{\circ} 4$, Springer, diciembre.

(2005), "Exporting and performance: evidence from Chilean plants", Canadian Journal of Economics, vol. 38, $\mathrm{N}^{\circ} 4$, Quebec, Canadian Economics Association.

Álvarez, R. y S. Vergara (2013), "Trade exposure, survival and growth of small and medium-size firms", International Review of Economics \& Finance, vol. 25(C), Amsterdam, Elsevier.

Audretsch, D. y T. Mahmood (1995), "New firm survival: new results using a hazard function", The Review of Economics and Statistics, vol. 77, $\mathrm{N}^{\circ} 3$, Cambridge, Massachusetts, The MIT Press, agosto.

Baldwin, R., R. Lipsey y J. Richards (1998), Geography and Ownership as Bases for Economic Accounting, Chicago, The University of Chicago Press.

Bandick, R. (2010), "Multinationals and plant survival", Review of World Economics, vol. 146, $\mathrm{N}^{\circ} 4$, Springer.

Barbosa, N. y H. Louri (2005), "Corporate performance: does ownership matter? A comparison of foreign- and domesticowned firms in Greece and Portugal", Review of Industrial Organization, vol. 27, $\mathrm{N}^{\circ} 1$, Springer.

Benvignati, A. (1987), "Domestic profit advantages of multinational firms", The Journal of Business, vol. 60, $\mathrm{N}^{\circ} 3$, Chicago, The University of Chicago Press, julio.

Bernard, A. y F. Sjoholm (2003), "Foreign owners and plant survival", NBER Working Papers, $\mathrm{N}^{\circ} 10039$, Cambridge, Massachusetts, National Bureau of Economic Research.

Blomström, M. (1988), "Labor productivity differences between foreign and domestic firms in Mexico", World Development, vol. 16, $\mathrm{N}^{\circ} 11$, Amsterdam, Elsevier, noviembre.

Blomström, M. y F. Sjöholm (1999), "Technology, transfer and spillovers: does local participation with multinationals matter?", European Economic Review, vol. 43, № 4-6, Amsterdam, Elsevier.

Caves, R.E. (1996), Multinational Enterprise and Economic Analysis, Cambridge, Cambridge University Press.

Cefis, E. y M. Ciccarelli (2005), "Profit differentials and innovation", Economics of Innovation and New Technologies, vol. 14, $\mathrm{N}^{\circ} 1-2$, Taylor \& Francis.

CEPAL (Comisión Económica para América Latina y el Caribe) (2012), La inversión extranjera directa en América Latina y el Caribe, 2011 (LC/G.2538-P), Santiago de Chile, junio. Publicación de las Naciones Unidas, $\mathrm{N}^{\circ}$ de venta: S.12.II.G.4. (2011), La inversión extranjera directa en América Latina y el Caribe, 2010 (LC/G.2494-P), Santiago de Chile, mayo. Publicación de las Naciones Unidas, $\mathrm{N}^{\circ}$ de venta: S.11.II.G.4. (2006), La inversión extranjera en América Latina y el Caribe, 2005 (LC/G.2309-P), Santiago de Chile, mayo. Publicación de las Naciones Unidas, $\mathrm{N}^{\circ}$ de venta: S.06.II.G.44. (2001), La inversión extranjera en América Latina y el Caribe, 2000 (LC/G.2125-P), Santiago de Chile, abril. Publicación de las Naciones Unidas, $\mathrm{N}^{\circ}$ de venta: S.01.II.G.12.

Cimoli, M. y otros (2005), "Cambio estructural, heterogeneidad productiva y tecnología en América Latina", Heterogeneidad estructural, asimetrías tecnológicas y crecimiento en América Latina, M. Cimoli (ed.), Santiago de Chile, Comisión Económica para América Latina y el Caribe (CEPAL)/Banco Interamericano de Desarrollo (BID).
Cohen, S.D. (2007), Multinational Corporations and Foreign Direct Investment: Avoiding Simplicity, Embracing Complexity, Nueva York, Oxford University Press.

Crespi, G., C. Criscuolo y J. Haskel (2006), "Information technology, organizational change, and productivity growth", Working Papers, $\mathrm{N}^{\circ}$ 558, Londres, Queen Mary University of London.

Dimelis, S. y H. Louri (2002), "Foreign ownership and production efficiency: a quantile regression analysis", Oxford Economic Papers, vol. 54, $\mathrm{N}^{\circ} 3$, Oxford, Oxford University Press.

Doms, M., T. Dunne y M. Roberts (1995), "The role of technology use in the survival and growth of manufacturing plants", International Journal of Industrial Organization, vol. 13, $\mathrm{N}^{\circ} 4$, Amsterdam, Elsevier, diciembre.

Dunning, J.H. (2000) "The ecletic paradigm as an envelope for economic and business theories of MNE activity", International Business Review, vol. 9, $\mathrm{N}^{\circ}$ 2, Amsterdam, Elsevier.

Gallagher, K. y D. Chudnovsky (2009), Rethinking Foreign Investment for Sustainable Development. Lessons from Latin America, Londres, Anthem Press.

Girma, S., R. Kneller, y M. Pisu (2005), "Export versus FDI: an empirical test", Review of World Economics, vol. 141, $\mathrm{N}^{\circ} 2$, Springer.

Godart, O., H. Görg y A. Hanley (2011), "Surviving the crisis: foreign multinationals vs domestic firms in Ireland", IZA Discussion Paper Series, $\mathrm{N}^{\circ}$ 5882, Institute for the Study of Labour, Bonn, julio.

Görg, H. y E. Strobl (2003), "Footloose' multinationals?", The Manchester School, vol. 71, $\mathrm{N}^{\circ}$ 1, John Wiley \& Sons, enero.

Hobday, M. y H. Rush (2007), "Upgrading the technological capabilities of foreign transnational subsidiaries in developing countries: the case of electronics in Thailand", Research Policy, vol. 36, $\mathrm{N}^{\circ}$ 9, Amsterdam, Elsevier.

Koenker, R. (2005), Quantile Regression, Nueva York, Cambridge University Press.

Kumar, N. (1990), "Mobility barriers and profitability of multinational and local enterprises in Indian manufacturing", The Journal of Industrial Economics, vol. 38, $\mathrm{N}^{\circ}$ 4, Wiley, junio.

Levinsohn, J. y A. Petrin (2003), "On the micro-foundations of productivity growth", noviembre, inédito.

Lipsey, R. (2002), "Home and host country effects of FDI", NBER Working Paper, $\mathrm{N}^{\circ}$ 9293, Cambridge, Massachusetts, National Bureau of Economic Research, octubre.

Love, J.H., S. Roper y J. Du (2009), "Innovation, ownership and profitability", International Journal of Industrial Organization, vol. 27, $\mathrm{N}^{\circ} 3$, Amsterdam, Elsevier.

Marín, A. y V. Arza (2009), "The role of multinational corporations in innovation systems of developing countries. From technology diffusion to international involvement", Handbook of Innovation Systems and Developing Countries. Building Domestic Capabilities in a Global Context, B. Lundvall y otros (eds.), Cheltenham, Edward Elgar.

Markusen, J.R. (2002), Multinational Firms and the Theory of International Trade, Cambridge, Massachusetts, The MIT Press.

Mata, J. y P. Portugal (2002), "The survival of new domestic and foreign-owned firms", Strategic Management Journal, vol. 23, $\mathrm{N}^{\circ}$ 4, John Wiley \& Sons, abril.

Moran, T., M. Graham y M. Blomstrom (2005), Does Foreign Direct Investment Promote Development?, Washington, D.C., Peterson Institute for International Economics.

Narula, R. y S. Lall (eds.) (2006), Understanding FDI-Assisted Economic Development, Nueva York, Routledge.

Olley, S. y A. Pakes (1996), "The dynamics of productivity in the telecommunications industry", Econometrica, vol. 64, $\mathrm{N}^{\circ} 6$, Nueva York, The Econometric Society. 
Ramstetter, E. (1998), "Comparisons of foreign multinationals and local firms in Asian manufacturing over time", Working Papers Series, vol. 98-18, Kitakyushu, The International Centre for the Study of East Asian Development.

Temouri, Y., N.L. Driffield y D. Higón (2008), "Analysis of productivity differences among foreign and domestic firms: evidence from Germany", Review of World Economics, vol. 144, $\mathrm{N}^{\circ} 1$, Springer.

UNCTAD (Conferencia de las Naciones Unidas sobre Comercio y Desarrollo) (2005), World Investment Report 2005:
Transnational Corporations and the Internationalization of $R \& D$ (UNCTAD/WIR/2005), Ginebra, Naciones Unidas. Publicación de las Naciones Unidas, $\mathrm{N}^{\circ}$ de venta: E.05.II.D.10.

Van Biesebroeck, J. (2005), "Firm size matters: Growth and productivity growth in African manufacturing", Economic Development and Cultural Change, vol. 53, $\mathrm{N}^{\circ} 3$, Chicago, University of Chicago Press.

Wagner, J. (2007), "Exports and productivity: a survey of the evidence from firm-level data", The World Economy, vol. 30, $\mathrm{N}^{\circ} 1$, Wiley Blackwell. 